\title{
Observations on larval fish transport and retention on the Scotian Shelf in relation to geostrophic circulation
}

\author{
C. S. REISS, ${ }^{1,2}, *$ G. PANTELEEV $, 2,4$ \\ C. T. TAGGART, ${ }^{2}$ J. SHENG ${ }^{2}$ AND \\ B. deYOUNG ${ }^{3}$ \\ ${ }^{1}$ Department of Biology, Dalhousie University, Halifax, NS, \\ Canada B3H 4J1 \\ ${ }^{2}$ Department of Oceanography, Dalhousie University, Halifax, \\ NS, Canada B3H 4J1 \\ ${ }^{3}$ Department of Physics and Physical Oceanography, \\ The Memorial University of Newfoundland, St Johns, NF, \\ Canada A1B 3 X7 \\ ${ }^{4}$ Shirshov Institute of Oceanology, Moscow, Russia 117218
}

\begin{abstract}
We draw inferences about the dynamic processes responsible for the dispersal of ichthyoplankton on small marine banks using physical and biological data derived from static point-estimates of water-mass characteristics and ichthyoplankton collected concomitantly on the central Scotian Shelf. Where the density field evolves slowly and ageostrophic forcing is weak, the near-surface geostrophic flow can be derived from hydrographic data using the dynamic height method modified for shallow seas. We assess our interpretations of larval distributions using simple particle tracking. The hydrography of the Scotian Shelf during November of 1997 was typical of late autumn, when density is determined by surface variation in salinity. Surface isopycnals generally paralleled isobaths, and there was no evidence of strong surface fronts. Sizes of larvae of pelagic origin (e.g. cod and hake) on Western Bank (sole spawning source) increased and became skewed towards larger animals (cod, 3-10 mm; hake, $5-15 \mathrm{~mm}$ ) in water-mass (Temperature and Salinity) space along isopycnals, consistent with gradual mixing and limited transport in the geostrophic flow (i.e. retention). Conversely, larvae of benthic origin (e.g. herring, 6-25 mm) were distributed across water-mass space, consistent with multiple origins and substantial transport. Our results
\end{abstract}

*Correspondence. e-mail: reiss@phys.ocean.dal.ca

Received 10 August 1999

Revised version accepted 20 March 2000 indicate that dispersal from small, low-energy marine banks results from the interaction of spawning location, geostrophic currents and bathymetric steering, and requires neither convergence nor larval behaviour.

Key words: Atlantic herring, circulation, Clupea harengus, cod, diagnostic calculation, Gadus morhua, Hake, marine banks, Merluccius billinearis, operational oceanography, optimal interpolation, retention, Scotian Shelf, transport, variational algorithm

\section{INTRODUCTION}

Most commercially important finfish in the north-west Atlantic use marine banks for spawning and as nurseries in the first year of life (Bolz and Lough, 1984; O'Boyle et al., 1984; Smith and Morse, 1985; Campana et al., 1989; Suthers and Frank, 1991). Several physical processes have been hypothesized to explain geographical persistence of fish eggs and larvae on marine banks. Clockwise gyre-like circulations on Georges and Browns Banks have been used to infer retention (i.e. decreased dispersion) as the mechanism that explains the observed persistence (Bolz and Lough, 1984; Smith and Morse, 1985; Loder et al., 1988; Suthers and Frank, 1991). Fronts (transition regions between mixed and stratified water masses) surrounding banks have also been suggested to form distinct zones of separation (between water masses) or aggregation (convergence zones) of larval fish and their prey (Kingsford, 1990). In tidally energetic areas, tidal fronts (sensu Pingree et al., 1974) and variations therein are hypothesized to play a significant role in larval dispersal and possibly recruitment processes (Iles and Sinclair, 1982; Sinclair and Iles, 1985; Heath et al., 1988; Chenoweth et al., 1989; Heath, 1990).

The mechanisms responsible for the putative retention of ichthyoplankton on smaller banks that are not strongly influenced by tidal mixing or rectification (e.g. Loder et al., 1988) are not easily identified. O'Boyle et al. (1984) hypothesized that clockwise gyres might be important on the smaller banks on the Scotian Shelf. Sanderson (1995) and Taggart et al. (1996) described a gyre-like water mass of intermediate salinity that contained high concentrations of 
larval fish on the crest of Western Bank, Scotian Shelf, though it was not clear whether a surface thermohaline front or geostrophic circulation was the principal mechanism leading to the physical retention of larval fish (Lochmann et al., 1997). The difference between the two mechanisms is important for modelling and prediction. For example, Cong et al. (1996) used a 3-dimensional shelf-circulation model driven barotropically by wind and baroclinically by a steady density field (a seasonal average) to calculate annual variations in spatially explicit retention indices for the Scotian Shelf. Their results demonstrated that retention was consistently associated with some of the smaller banks on the Shelf, although the model could not accommodate frontal mechanisms.

The hypothesis that the numbers of marine fish populations depends on the size of larval retention areas (Iles and Sinclair, 1982; Sinclair and Iles, 1985; Sinclair, 1988) has influenced the direction of fisheries oceanographic research. The 'retention' hypothesis is a re-scaling of the match-mismatch (Cushing, 1973) and critical period (Hjort, 1914) hypotheses, and is modified to accommodate geographical features (see Cushing, 1990). Testing the validity of the retention hypothesis requires the biological and physical sampling schemes to be appropriately scaled (space and time) because retention and dispersal may appear to be scale-dependent (Taggart and Frank, 1990), and may actually be so (Okubo, 1993). Persistence resulting from physical processes is distinct from that driven by biological processes (though they can interact). For example, spatially determined differential survival (biologically driven) may produce evidence of persistence that is indistinguishable from physically driven persistence that can result from circulation and convergence, although the bases for making and testing resultant predictions are entirely different (Polgar, 1981; Lochmann et al., 1997). Therefore, we ask, is it possible to draw inferences about the dynamic processes involved in larval dispersal when typical fisheries oceanography data are derived from static point-estimates of biological characteristics (larval species, concentration, size, etc.) and water-mass characteristics (depth, temperature, salinity, density, etc.)?

The central Scotian Shelf is an ideal location to address the above question and to examine aspects of the retention hypothesis. The numerous small offshore banks and their associated fish species with demersal and pelagic spawning strategies allow a range of comparisons to be made. The dominant spatial scales on the Scotian Shelf are determined by bathymetric features (banks, basins, channels, etc.) because bathymetric steering influences shelf circulation (Hannah et al.,
2000). The spatial correlation scales of water-mass structure and circulation during the autumn-winter period on Western Bank (a typical small-scale bank) are $\approx 40 \mathrm{~km}$ along-shelf and $\approx 15 \mathrm{~km}$ across-shelf (Sheng and Thompson, 1996). Accordingly, questions of bank-scale larval dispersion must be addressed by examining biological and hydrographic features at scales relevant to the bank in question. At small-bank scales, the ability to resolve the circulation in near realtime is critical to addressing dispersion (Helbig and Pepin, 1998a,b). We therefore developed a hierarchical sampling scheme (shelf- and bank-scale) to examine the role that physical and biological processes might play on the central Scotian Shelf in explaining the spatial distributions of abundance and size of larval fish.

We examine relations between the abundance and size distributions of larval fish and their physical environment in a complementary manner. We first examine larval fish assemblages and their relation to water masses. We then determine if more information is available by examining the spatial distribution of assemblage members in a dynamic sense, deriving the near-surface circulation directly from hydrographic data using the dynamic height method. This allows us to determine the roles that water-mass mixing and advection play in generating the observed spatial distributions of larvae. We assess the validity of our interpretations with a simple particle-tracking exercise. Finally, we suggest that under certain conditions, the dynamic height method provides a useful first approximation of the circulation field in shelf seas (where most fish species spawn) that can be used to improve sampling design, and we recommend that resolving the circulation, at the time of sampling can lead to adequate and critical tests of retention-related hypotheses.

\section{METHODS AND MATERIALS}

\section{Ichthyoplankton}

Larval fish and hydrographic data were collected across the Scotian Shelf during 18 November to 1 December 1997 (Power, 1998). In all, 84 ichthyoplankton samples were collected across a broad-scale grid of 88 stations ( $25 \mathrm{~km}$ spacing) augmented by higher-resolution sampling over the smaller banks (Fig. 1). Plankton were collected using the netminder-II (Bedford Institute of Oceanography, Dartmouth, NS), which consists of a standard $61 \mathrm{~cm}$ diameter bongo frame (Posgay and Marak, 1980) fitted with $333 \mu \mathrm{m}$-mesh nets and an electronics package that sends pressure $(p)$, temperature $(T)$, pitch, roll and filtered-volume data for computer logging and display 
Figure 1. Bathymetric $(\mathrm{m})$ chart of the Scotian Shelf, showing locations of major landmarks, biological and hydrographic sampling stations (solid circles) along transects nos 1-11, current meter moorings (solid diamonds) on Western Bank (WB), and the cross-shelf (no. 5) and detailed cross-bank hydrographic sections (solid lines) occupied during 18 Nov. to 01 Dec. 1997.

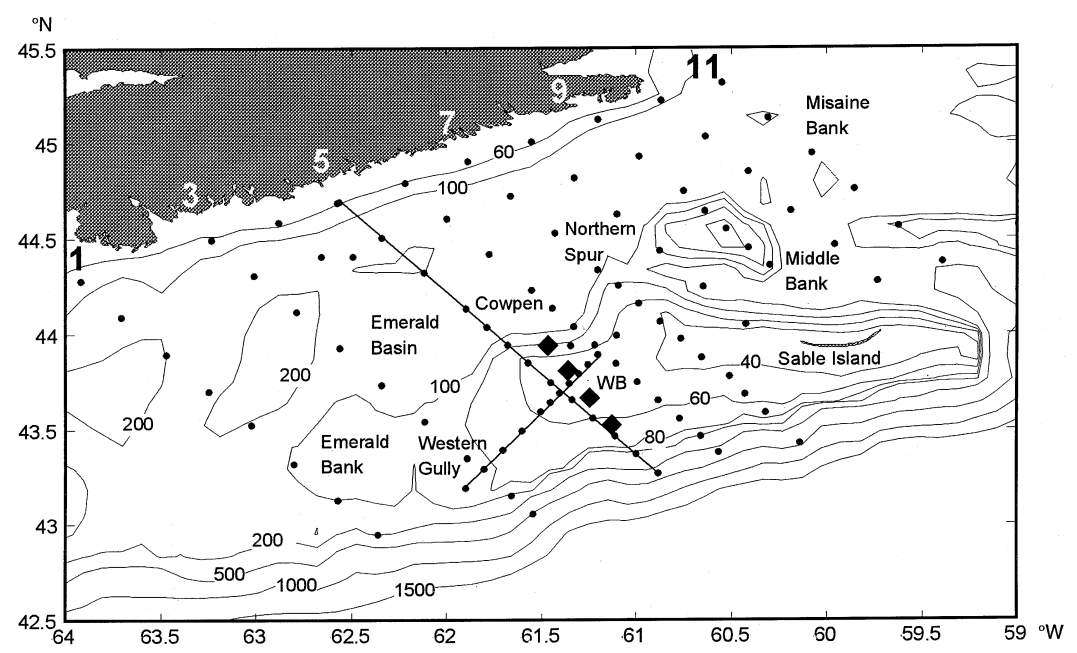

at $2 \mathrm{~Hz}$. The gear was generally towed at $\approx 1 \mathrm{~m} \mathrm{~s}^{-1}$ in a double-oblique manner to within $5-10 \mathrm{~m}$ of the bottom. On retrieval, each of the two net collections was preserved in 5\% (vol:vol) buffered-formalin:seawater.

Larval fish were identified to species and enumerated (concentration: per $100 \mathrm{~m}^{3}$ ). We reserve the term density $\left(\mathrm{kg} \mathrm{m}^{-3}\right)$ as a water-mass variable. Larvae were measured as total length (TL; $\pm 0.1 \mathrm{~mm}$ ) for preflexion larvae and as standard length (SL; $\pm 0.1 \mathrm{~mm})$ and TL for flexion and postflexion larvae. Ichthyoplankton assemblages were determined using principal component analyses (PCA) of the most abundant taxa as in Suthers and Frank (1991). Variations in larval abundance and size within and among the dominant species of silver hake (Merluccius bilinearis), Atlantic herring (Clupea harengus harengus), and Atlantic cod (Gadus morhua) were examined in relation to water-mass temperature (T), salinity $(\mathrm{S})$ and density ( $\rho$ or $\sigma_{t}$ as required) among stations. In many cases, statistical tests for pattern discrimination were unnecessary.

\section{Hydrography}

Hydrographic data were collected at each station and along a fine-scale $(\approx 8 \mathrm{~km}$ spacing) hydrographic transect $(\approx 85 \mathrm{~km})$ from the SW flank of Emerald Bank to the crest of Western Bank (Fig. 1) using a Seabird Electronics SBE 25e CTD (Larson, 1993). These data included conductivity, $\mathrm{T}$ and $p$ that were used to derive depth $(z), S, \rho$ and subsequently dynamic height ( $\eta$, see below). We constructed sections and surface charts of $\mathrm{T}, \mathrm{S}, \sigma_{t}$ and $\eta$ as needed using a conservative Kriging method (SURFER version 6.04, Golden Software, Golden, CO).

The dynamic height method

Surface layer circulation was inferred using the dynamic height method of Helland-Hansen (1934) as modified by Csanady (1979) and by Sheng and Thompson (1996), where the relative height of the water column is estimated from density across an entire shelf, including regions of complex bathymetry. Estimates of dynamic height and the surface geostrophic current over the shelf are derived from the spatially scattered density profiles. In essence, the method directly estimates velocity shear. There are two major limitations: (1) only near-surface geostrophic flow (relative to a reference level) is estimated; and (2) neither depth-independent tidal flow nor barotropic flow (independent of the density field) is included. Some portion of wind-driven flow is included in the estimates, and it is dependent on the internal response and time for adjustment for the entire system.

Calculating dynamic height $(\eta)$ in this manner involved four steps (Sheng and Thompson, 1996). First, density near the bottom $\left(\rho_{h}\right.$; hereafter referred to as bottom-density) is determined from the density profile at each station. It is important that the CTD profiles extend to near-bottom $(<2 \mathrm{~m})$ for adequate estimates of $\rho_{h}$. Second, an idealized and functionally stable (i.e. $\rho$ increases with $z$ ) bottom-density profile $\rho_{\text {id }}(z)$ is constructed from all available $\rho_{h}$ values among the spatially irregular profiles (stations) using a general curve-fitting routine. Third, the idealized nearbottom density profile is appended to each observed density profile, to extend the profile to a chosen level of no motion $\left(-h_{0}\right)$ and a set of extended density profiles $\rho(z)$ are created for $-h_{0} \leq z \leq 0$. Finally, the dynamic height of the water column relative to $-h_{0}$ is calculated at each station using:

$$
\eta=-\left(\frac{1}{\rho_{0}}\right) \int_{-h_{0}}^{0} \rho(z) \mathrm{d} z
$$


where $\rho_{0}$ is the reference density (we used $1028.1063 \mathrm{~kg} \mathrm{~m}^{-3}$ ). Our results showed a weak dependence on the choice of $-h_{0}$ that was varied between 200 and $400 \mathrm{~m}$ before selecting $-h_{0}=250 \mathrm{~m}$, as most of the region is less than $200 \mathrm{~m}$ deep. Note, in eqn 1 the hydrostatic approximation has been used and it allows us to write the pressure term $(\mathrm{d} p)$ in terms of depth $(\mathrm{d} z)$. This application requires some knowledge of the region and a stable bottom-density profile is required as in Fig. 2(a). The main assumption of the dynamic height estimation is that bottom-density, $\rho_{h}$, does not vary greatly along isobaths, an assumption Sheng and Thompson (1996) validated for the Scotian Shelf during autumn and winter. The assumption may not hold for all places at all times. Further, if barotropic or wind-driven circulation dominate, then the method is not applicable. It is applicable on the Scotian Shelf in autumn to spring as baroclinic terms dominate the barotropic terms (Han et al., 1997).

\section{Dynamic height estimation}

Using the bottom density data shown in Fig. 2(a), we fit an idealized exponential model:

$$
\rho_{\text {id }}(z)=\mathrm{a} /\{1+\mathrm{b}(\mathrm{e}[\exp (-\mathrm{cz})])\}
$$

where $\rho_{\text {id }}$ is the idealized density at depth $(z)$ and a, b, and $\mathrm{c}$ are fitting coefficients. Comparison of the resultant velocity fields with those derived using a piecewise linear fit showed root-mean-square error differences $<15 \%$. Thus, for our data, it makes little difference how the profile is fitted. However, other data may require different fitting routines, e.g. it would be appropriate to fit distinct profiles in cases where the 'inshore' bottom density is substantially less than that 'offshore'.

As cautioned above, the dynamic height method explicitly neglects barotropic, tidal and wind-driven contributions, although some unknown portion of wind-driven flow is incorporated. To assess the contribution of wind stress, we calculated the Ekman transport vector $S_{e}=\left(S_{x}, S_{y}\right)$ using:

$$
S_{x}=\tau_{y} /\left(f \rho_{0}\right) \text { and } S_{y}=-\tau_{x} /\left(f \rho_{0}\right)
$$

where $\tau=\left(\tau_{x}, \tau_{y}\right)$ is the wind stress vector at the sea surface, and $f$ is the Coriolis parameter (for Western Bank, $\approx 45^{\circ} \mathrm{N}, f$ is $\left.1.0284 \times 10^{-4} \mathrm{~s}^{-1}\right)$. Using an average value of $|\tau| \approx 0.1 \mathrm{~N} \mathrm{~m}^{-2}$, and a surface Ekman layer of $40-50 \mathrm{~m}$, the depth-averaged wind-driven component of the total current is about $2 \mathrm{~cm} \mathrm{~s}^{-1}$. The influence will be substantially reduced at the base of the mixed layer (Ekman currents decrease with depth).
Figure 2. (a) Density $\left(\sigma_{t}\right)$ at the bottom as a function of depth at bottom as determined from CTD casts among sampling locations (Fig. 1) on the Scotian Shelf during 18 Nov. to 01 Dec. 1997; and (b) density $\left(\sigma_{t}\right)$ profiles at Stn-11 $\left(43.55^{\circ} \mathrm{N}, 62.11^{\circ} \mathrm{W} ; 21\right.$ Nov. 1997$)$ and Stn-93 (43.30 $\mathrm{N}$, 61.80W; 30 Nov. 1997).

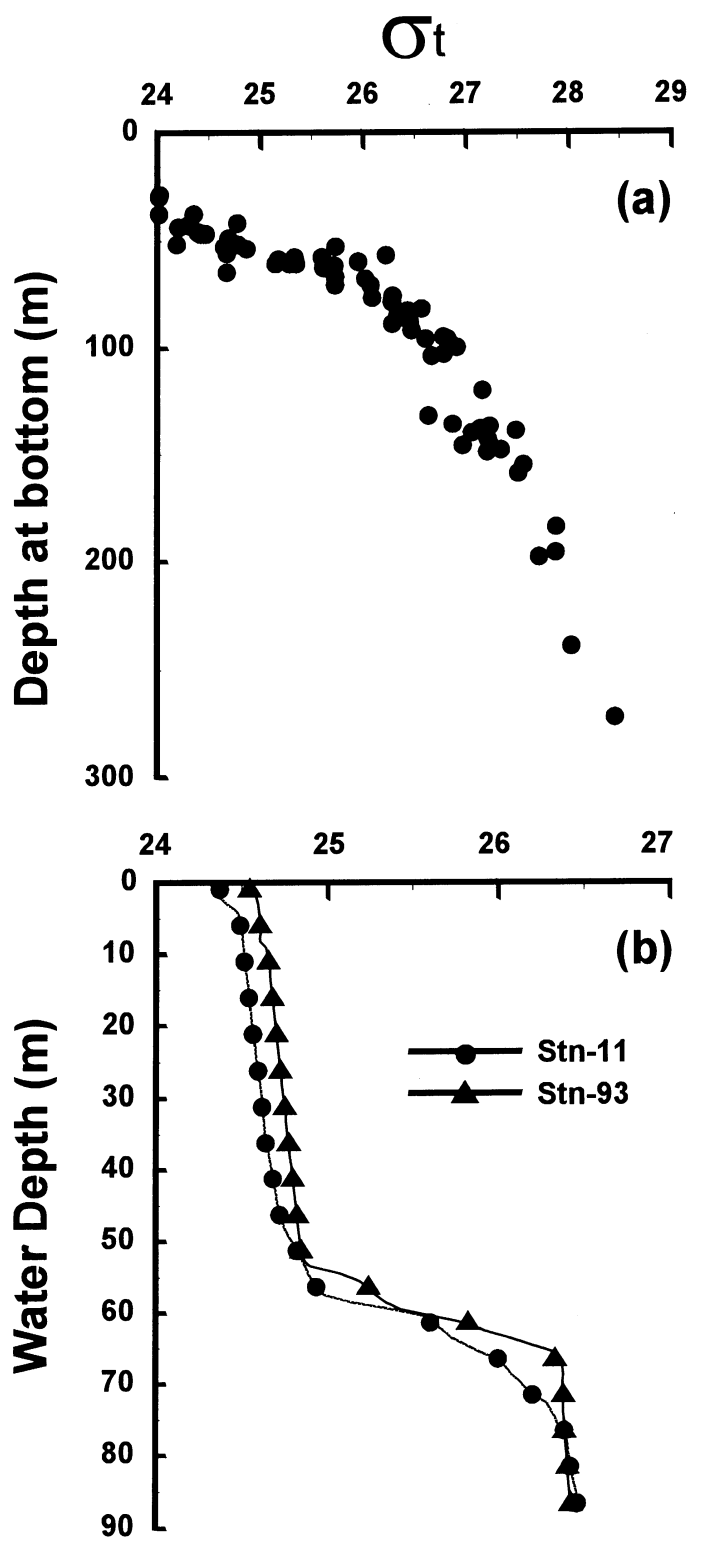

The density-driven currents from the dynamic height method around Western Bank are estimated at nearly $10 \mathrm{~cm} \mathrm{~s}^{-1}$ (see below) - fivefold greater than the wind-driven component. As well, Han et al. (1997) showed that, along a central Shelf section orientated perpendicular to the coast, $>90 \%$ of the monthly average transport was related to the baroclinic pressure gradient. Thus, at periods of $\approx 10$ days and greater, 
ignoring the influence of wind and tidally rectified flow on subtidal circulation on the Scotian Shelf is justified.

The flow-field derived from the dynamic height method is stationary, while in reality it is not. Griffin and Thompson (1996) showed that the advection of salt and heat can significantly alter the density field on the Scotian Shelf in as little as 8 days. However, a comparison of density profiles, separated by $\approx 9$ days during our study, shows a small change in surface density (Fig. 2b). Thus, we assume that the error arising from changes in the density field lie within the range of the error generated by ignoring wind and tidal forcing. The assumption is reasonable from a biological perspective, because the error associated with plankton sampling typically approaches 40\% (Posgay and Marak, 1980).

\section{Surface geostrophic flow estimation}

We used two different approximations to estimate geostrophic flow in the surface layer. The simplest was an optimal interpolation (Gandin, 1965) of the dynamic height estimates from the irregularly spaced station-profiles to a regular grid. A Gaussian correlation function was used:

$$
F(r)=e\left(\exp \left(-r / L_{0}\right)^{2}\right)
$$

where $r$ is the scaling radius for the interpolation and $\mathrm{L}_{0}$ is a fixed uniform correlation scale set at $35 \mathrm{~km}$, consistent with empirical estimates of the along-shelf de-correlation scale (Sheng and Thompson, 1996; Han et al., 1997). The flow field was then directly estimated from the dynamic height grid using thermal wind equations (Gill, 1982; Pond and Pickard, 1983):

$$
u=-g \eta_{y} / f \quad \text { and } \quad v=g \eta_{x} / f
$$

where $u$ and $v$ are the east and north components of the surface geostrophic flow, $g$ is the gravitational constant, and $\eta_{x}$ and $\eta_{y}$ are the corresponding derivatives of $\eta$ from eqn 1 .

A better approximation was generated using a variational interpolation algorithm (Panteleev and Yaremchuk, 1989). This method is superior in resolving small-scale circulation features because weighting functions related to the correlation scales are neither fixed nor set a priori as above. The current is calculated by applying the thermal wind equations to the irregularly distributed observations of $\mathrm{T}$ and $\mathrm{S}$. The resultant velocity estimates (not on a regular grid as above) are put into the variational algorithm that treats the interpolation of the velocity field as a weak constraint problem (Sasaki, 1970). In essence, the technique assimilates the velocity information by minimizing a series of cost functions that include divergence, nonlinear advection of the resulting velocity fields and a smoothing function. Furthermore, $\mathrm{L}_{0}$ is estimated during the analysis (Gandin, 1965; McIntosh, 1990). Error analyses showed $\mathrm{L}_{0}$ to be $\approx 33 \mathrm{~km}$, similar to that previously estimated (Sheng and Thompson, 1996; Han et al., 1997). As the surface currents are virtually geostrophic on the Scotian Shelf in autumn (i.e. nonlinear terms are small), and as the along-current spatial correlation-scale is greater than the across-current scale, minimizing the nonlinear velocity-advection terms has both a physical and a mathematical justification. The two interpolation techniques are directly comparable because they rely on the same initial data. The optimal technique is a statistical interpolation and the variational technique is a dynamical interpolation, and the latter should produce superior results where the flow is primarily geostrophic.

\section{Particle tracking}

We used a simple particle-tracking model based on the derived flow field to assess the hypothesis that the observed spatial distribution of larval fish is most easily explained by spawning location and circulation. 'Particles' were 'released' along transects within a sampling grid and were tracked for 20 days. The utility of the simulation is based on three assumptions. First, as the dynamic height calculation reflects the average surface $(0-40 \mathrm{~m})$ currents, we constrain the particles to the surface layer. We did not impose temporal variation in vertical distribution, as all three species (cod, hake, and herring) have been collected within the mixed layer that extends to $\approx 40$ or $50 \mathrm{~m}$. There is little evidence of variation in the depth distribution for early-stage cod and hake in the Western Bank region (Taggart et al., 1996 and Lochmann et al., 1997 for cod; Fortier and Villeneuve, 1996 for hake; and our unpublished data for both). There are no reliable data for the vertical distribution of herring larvae on the Scotian Shelf. However, in other regions, herring may exhibit diel or semidiel vertical distribution patterns, but they are limited to the mixed water column (Stephenson and Power, 1988, 1989). Second, although the circulation as derived does not evolve in time ( $\approx 13$ days in this study), we assume the method provides a valid approximation commensurate with the temporal and spatial biological sampling scales. The assumption rests on the observation that the density-driven currents vary slowly over periods of days to weeks on the Shelf (Sheng and Thompson, 1996) and are within the limits of the sampling error 
as detailed above. Third, the stationary flow field can only be hypothesized to reflect the distribution of larval size and abundance if larval growth is sufficient to be measurable within the period over which the flow field is derived. Early stages of cod larvae would double their length in $10-15$ days $\left(\approx 0.14 \mathrm{~mm} \mathrm{day}^{-1}\right.$; Meekan and Fortier, 1996), herring in 15-22 days $\left(\approx 0.33 \mathrm{~mm} \mathrm{day}^{-1}\right.$; Bolz and Burns, 1996), and hake in $10-15$ days $\left(\approx 0.2 \mathrm{~mm} \mathrm{day}^{-1}\right.$; Jeffrey and Taggart, in press). These periods are comparable to the above period of stationarity in the flow field.

\section{Definition of retention}

In this paper, we define larval retention as physical processes that lead to reduced dispersion of larvae. If retention processes occur in a given region of production over time (and in the absence of immigration from elsewhere), then the larval size-frequency distribution will be right-skewed towards larger sizes (Polgar, 1981), i.e. where spawning is protracted, retention will constrain the distribution of larvae such that multiple size classes will be observed in a limited area. Biologically mediated retention is a special case that may operate through vertical migration (Iles and Sinclair, 1982; Stephenson and Power, 1989) but, given our above definition, it serves only to reinforce the effects of primarily physically driven retention.

\section{RESULTS}

\section{Hydrography}

The hydrographic structure on the Scotian Shelf during November was dominated by broad-scale surface variation in T and S (Fig. 3a,b). Low-temperature $\left(<7^{\circ} \mathrm{C}\right)$ and low-salinity $(<30.5 \mathrm{psu})$ water extended along the coast and was separated from warmer $\left(>8^{\circ} \mathrm{C}\right)$ and more saline ( $>31 \mathrm{psu}$ ) water offshore. The surface layer on Western Bank was slightly cooler $\left(<7.5^{\circ} \mathrm{C}\right)$ and fresher (30.5-31.0 psu) relative to Emerald Basin.

The surface density variation was similar to that of surface salinity (Fig. 3c), indicating that $S$, rather than $T$, was the primary determinant of surface density ( $\mathrm{S}$ and $\sigma_{t}$ correlation $|\mathrm{r}|=0.9, P<0.001$ ). The highest-density surface water was in Emerald Basin, while around Western Bank the intermediate-density water extended to the north and north-east. Surface isopycnals paralleled the isobaths on the southern and western flanks of Western Bank and crossed the bathymetry on the north-western flank, effectively separating intermediate-density water to the east from the higher-density water to the west (Fig. 3c).

Hydrographic sections of T, S and $\sigma_{t}$ along transect 5 (see Fig. 1 for location) show typical autumnal water-mass characteristics (Fig. 4). The surface mixed layer extended to $\approx 60 \mathrm{~m}$ and intersected the bottom near the crest of the Bank. There was no evidence of strong surface fronts as observed by Taggart et al. (1996) and Lochmann et al. (1997), and the surface layer $\mathrm{T}, \mathrm{S}$ and $\sigma_{t}$ structure was generally uniform over the Bank. It is important to note that the isopycnals intersected the bottom at about the same depth on the flanks of the Bank, consistent with our assumption that the bottom density does not vary greatly along isobaths.

The hydrographic section from Emerald Bank to the crest of Western Bank also showed the water column to be mixed over the Bank (Fig. 5); the horizontal gradients in $\mathrm{T}, \mathrm{S}$, and $\sigma_{t}$ were weak, and there was no evidence of a surface frontal feature. The welldefined pycnocline at the base of the mixed layer intersected the bottom at the same depth $(\approx 60 \mathrm{~m})$ on the flanks of the Bank.

\section{Ichthyoplankton assemblages}

Thirteen larval fish species representing nine families were collected. Atlantic herring, Atlantic cod and silver hake were most abundant, while capelin (Mallotus villosus), sculpin (Myoxocephalus sp.), fourbeard rockling (Enchelyopsis cimbrius), pollock (Pollachias virens), red hake (Urophysis chuss) and sandlance (Ammodytes spp.) were sufficiently abundant to be useful in defining species assemblages.

Two larval fish assemblages, representing species with demersal and pelagic spawning strategies, were revealed using PCA ordination. The first three components $(\mathrm{C})$ explained $61 \%$ of the variance in the species matrix $\left(\mathrm{C}_{1}=30 \%, \mathrm{C}_{2}=19 \%, \mathrm{C}_{3}=\right.$ $12 \%) . C_{1}$ was negatively rank-correlated with surface-layer temperature $(-0.41, P<0.01), C_{2}$ was positively correlated with salinity $(0.39, P<0.01)$ and $C_{3}$ was negatively correlated with depth $(-0.27$, $P<0.02$ ). There were no other significant relationships between component scores and other state variables (distance offshore, $\mathrm{T}, \mathrm{S}, z, \sigma_{t}$ or $\eta$ ). $\mathrm{C}_{1}$ loadings (correlation between the abundance of each species and the component scores; Fig. 6) showed that one assemblage enveloped (strong negative correlation) the pelagic-spawning groundfish species (cod, silver hake and pollock) and the other enveloped (no correlation) $>90 \%$ of the benthic-spawning species (herring, capelin, sandlance, fourbeard rockling, sculpins, and red hake - only the last has pelagic eggs). This second assemblage was subdivided along the $\mathrm{C}_{2}$-loading into a benthic-spawning sandlance and herring group (strong positive correlation). 
Figure 3. Bathymetric charts of the Scotian Shelf showing surface $(5 \mathrm{~m})$ isopleths of temperature $\left({ }^{\circ} \mathrm{C}\right)$; salinity (psu); and density $\left(\sigma_{t}\right)$ as interpolated from CTD data collected among sampling locations (solid circles) during 18 Nov. to 01 Dec. 1997.
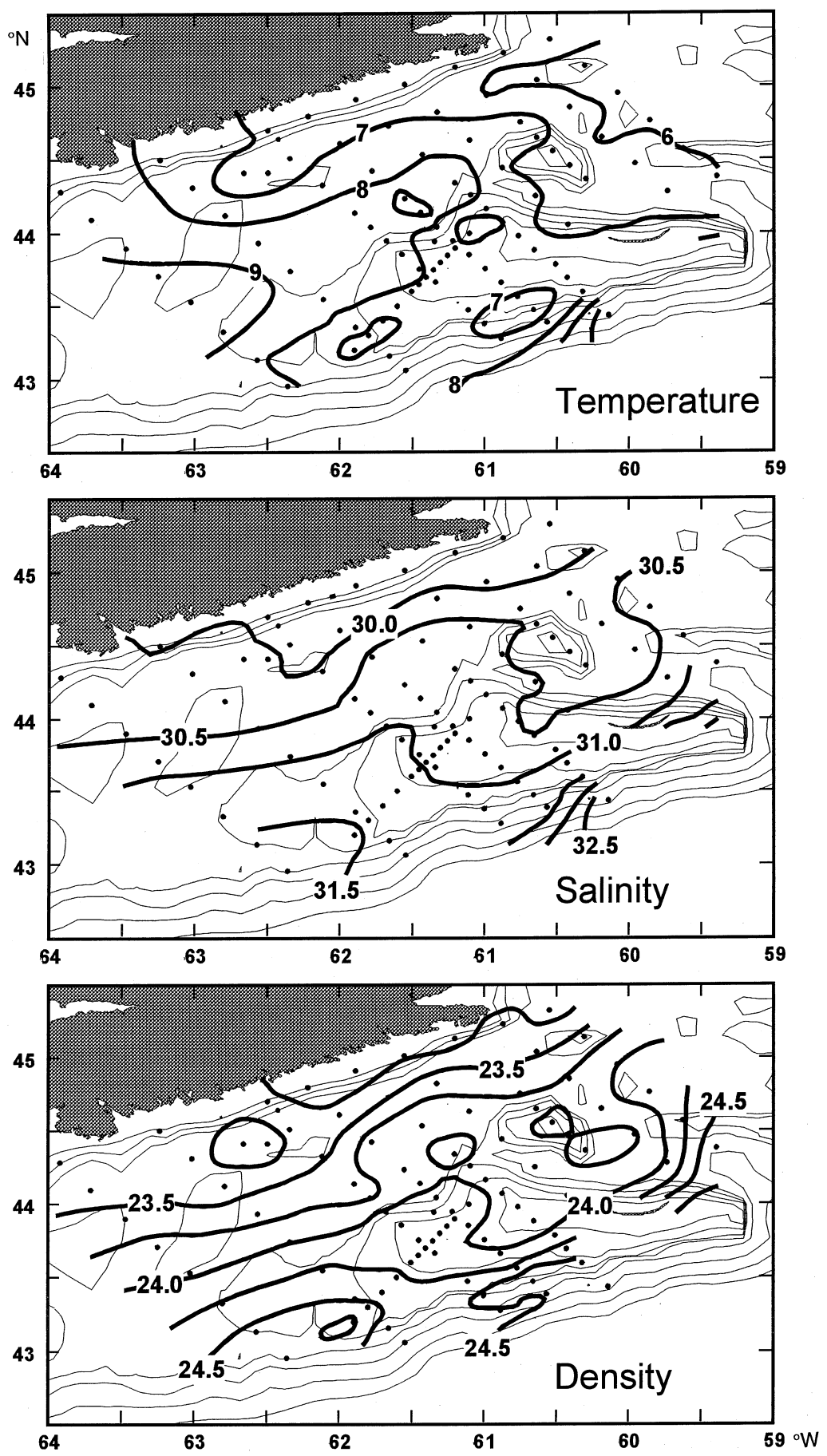

Larval fish and water-mass associations

Larvae of the pelagic-spawning assemblage were clearly constrained to water masses defined by surface (5 m) T, S and thus density (Fig. 7a,b,c,d). High concentrations of cod and hake larvae were associated with a 30.7 psu and $7.9^{\circ} \mathrm{C}$ near-surface water mass. For both species, high concentrations of smaller animals were associated with warmer and more saline water, while larger animals were associated with slightly fresher and colder water that was density-compensated (i.e. highest concentrations of cod and hake are associated with isopycnals - lines of constant density). Large cod (some $>8 \mathrm{~mm}$ TL) were associated with the lower-salinity, cooler water (Fig. 7b) and a similar pattern of association is apparent for hake (Fig. 7d) 


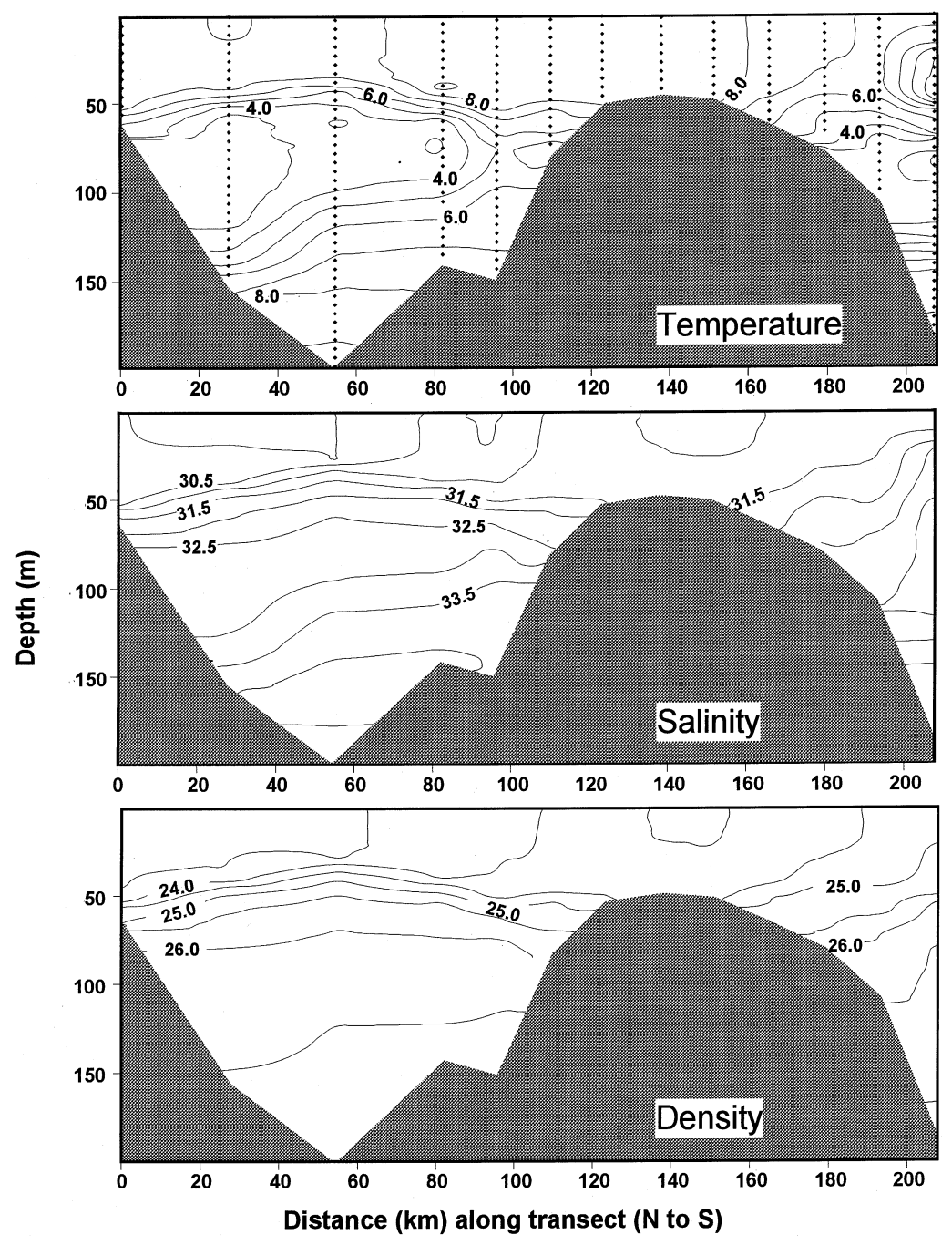

Figure 4. Temperature $\left({ }^{\circ} \mathrm{C}\right)$, salinity (psu), and density $\left(\sigma_{t}\right)$ sections along transect no. 5 (Fig. 1) from north to south across the central Scotian Shelf to Western Bank and the shelf break in November 1997. CTD profile data used for contouring isopleths are shown in the temperature section.

although the size-range (4-16 $\mathrm{mm} \mathrm{TL})$, and thus the age range, was greater than that of cod. Taken together, these data suggest that over time, both species were being mixed or advected into fresher and colder water of the same density.

Water-mass $\mathrm{T}$ and $\mathrm{S}$, and abundance associations, for bottom-spawned herring larvae were less defined (Fig. 7e). High concentrations of herring were associated with salinities ranging from 31 psu, i.e. two distinct maxima: one associated with the lowersalinity coastal water and the other associated with the higher-salinity water on Western Bank. The various size-classes of herring larvae were not constrained to any particular water mass, although the highest concentrations of small herring were associated with slightly cooler and fresher water masses and large herring were associated with all water masses (Fig. 7f).
Shelf- and bank-scale circulation

Contours of the dynamic height estimates (Fig. 8) reveal a pattern consistent with that of surface salinity and density (cf. Figure 3a,c). As the magnitude of the gradient across isopleths reflects the strength of the geostrophic current, the contours can be interpreted as streamlines; the closer the isopleths, the greater the gradient and the stronger the inferred surface current. The cross-shelf gradient in $\eta$ over the inner shelf $(0.41-0.37 \mathrm{~m})$ reflects the south-west flow of the Nova Scotia current. Strong cross-shelf gradients along the shelf-edge $(0.35-0.29 \mathrm{~m})$ reflect the stronger shelfslope current (Fig. 8). Around Western Bank, the isopleths follow the bathymetry along the southern and western flanks of the Bank, before turning northwest to run parallel to the coast similar to the density contours. This indicates that the surface geostrophic 
Figure 5. Temperature $\left({ }^{\circ} \mathrm{C}\right)$, salinity (psu), and density $\left(\sigma_{t}\right)$ sections along the detailed transect from SW to NE across Western Bank (see Fig. 1) in November 1997. CTD profile data used for contouring are shown in the temperature section.

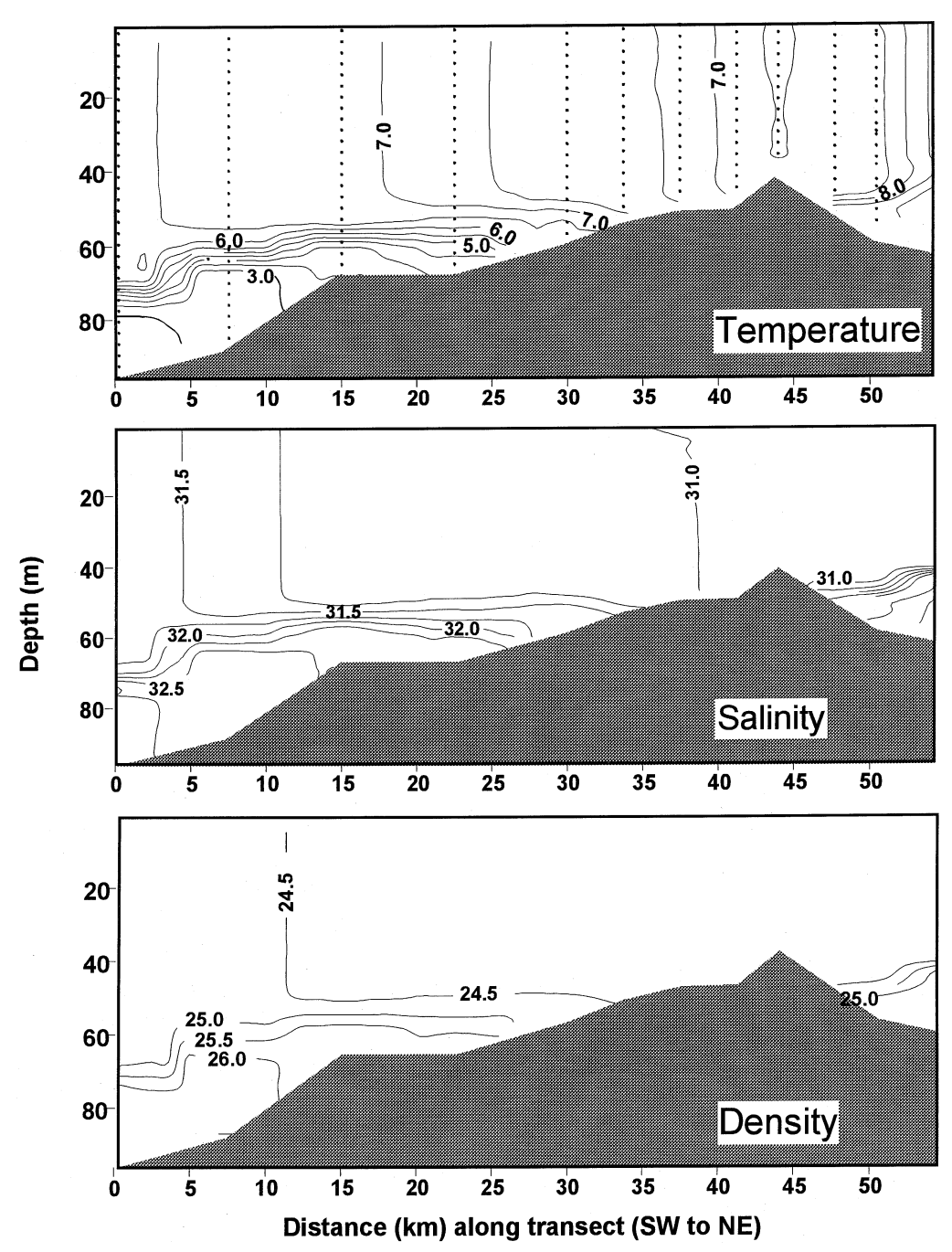

current flows northward over the western flank and eventually joins the Nova Scotia current. Over Emerald Basin and Emerald Bank, the cross-shelf gradients are small, indicating relatively low flow. On Western Bank and to the north, the gradients are also small, consistent with low velocities.

The flow fields estimated from the optimal (Fig. 9a) and variational (Fig. 9b) interpolations of dynamic height both reflect the general circulation of the central Scotian Shelf. Note that the latter provides a more detailed description of the circulation and has greater skill in reproducing the observed flow (see below). This is best demonstrated by comparing the magnitude and direction of the current meter measurements on Western Bank (averaged over the 13 day sampling period) with the predicted currents (Fig. 9c, d). For example, both observed and predicted currents are fairly weak $\left(<3 \mathrm{~cm} \mathrm{~s}^{-1}\right)$ eastward and south-eastward flows on the northern flank and near the crest of Western Bank. Similarly, on the southern flank of the Bank and near the shelf-edge a relatively strong $\left(5-7 \mathrm{~cm} \mathrm{~s}^{-1}\right)$ shelf-slope current was also observed and inferred.

We assessed the skill of each interpolation scheme with a $\gamma^{2}$ statistic using the time-averaged current meter velocity observations $\left(V_{\text {obs }} ; n=4\right)$ and all nearest neighbouring interpolated currents $\left(V_{\text {int }}\right.$; $n=4$ for the optimal interpolation; $n=9$ for the variational; see Fig. 9c,d) where:

$$
\gamma^{2}=\frac{\sum_{i=1}^{n}\left|V_{\text {obs }}-V_{\text {int }}\right|^{2}}{\sum_{i=1}^{n}\left|V_{\text {obs }}\right|^{2}}
$$

A similar definition of $\gamma^{2}$ was used by Thompson and Sheng (1997). We compared the $\gamma^{2}$ statistic with that obtained by permuting the observed current vectors across all combinations of the interpolated nearest neighbouring vectors. A $\gamma^{2}$-value of zero indicates that 
Figure 6. Factor loadings for the first two principal components from a PCA analysis of the most abundant larval fish species collected on the central Scotian Shelf during 18 Nov. to 01 Dec. 1997.

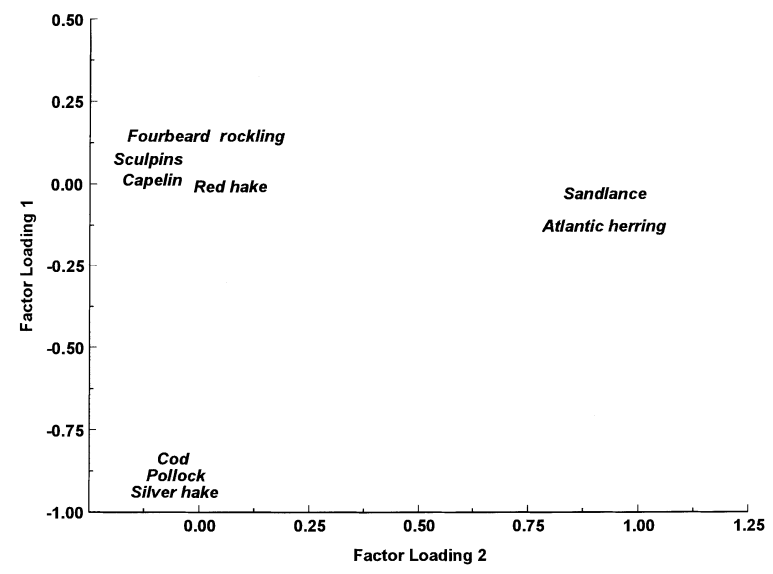

the interpolated vectors equal the field of observed vectors. A $\gamma^{2}$ value greater than unity implies no skill in the interpolation (i.e. no flow would do as well as the interpolation). For the optimal interpolation, $\gamma^{2}$ was 0.63 , and $23 \%$ of all possible combinations provided a lower estimate. Conversely, $\gamma^{2}$ for the variational interpolation was 0.37 , and $2 \%$ of all possible combinations provided a lower estimate. Thus, the variational interpolation is preferred in this case.

\section{Spatial distribution of ichthyoplankton}

Larval cod and silver hake (as well as pollock, not shown), regardless of size, were concentrated near Western Bank (Figs 10a and 11a) in the area of relatively low flow north-west of the crest seen in Fig. 9(b). Few larvae of any species (other than herring; see below) were found elsewhere on the central Scotian Shelf and the distributions of cod and hake larvae demonstrate a single offshore spawning location on the central Scotian Shelf. The spatial distribution of ontogenetic stages (size classes) of cod and silver hake (Figs 10b, 11b) reflect the $T$ and $S$ associations shown in Fig. 7. The abundant small cod and silver hake larvae $(<5 \mathrm{~mm})$ were concentrated near the crest of Western Bank in the region of low flow. The relatively rare large cod larvae ( $\approx 6-9 \mathrm{~mm}$ TL) and larger silver hake were primarily distributed off the northern flank in the north-eastern flow.

Herring larvae (regardless of size) were most concentrated ( $>50$ per $100 \mathrm{~m}^{3}$ ) along the $70 \mathrm{~m}$ isobath on the southern flank of Western Bank, and to a lesser extent along the coast of Nova Scotia (Fig. 12a). The spatial distribution of the size-classes of herring larvae across the Scotian Shelf indicates at least three spawning locations/populations (Fig. 12b). The smallest herring larvae ( $<6 \mathrm{~mm}$ TL) were most concentrated along the southern flank of Western Bank, reflecting a nearby spawning location. Larvae $<8 \mathrm{~mm}$ TL were also found along the coast, indicating local spawning sources. The largest herring $(\approx 15 \mathrm{~mm} \mathrm{TL})$ were uniformly distributed within the coastal current, and were also present north-east of Sable Island and where they likely reflect advection in the coastal current from an upstream spawning location.

\section{DISCUSSION}

The resolution of the near-surface shelf circulation and the bank-scale circulation was necessary to explain the patterns in larval fish distribution in this study. The observed ichthyoplankton distributions reflected spawning locations and the subsequent transport of larvae within the derived geostrophic currents. With the exception of herring near the coast, the smallest (and therefore youngest), cod, hake and herring larvae were found concentrated in the Western Bank region and provide evidence that this region is the dominant spawning location in autumn for all three species (Figs 10b, 11b, 12b). There was no evidence of other substantial spawning locations elsewhere on the central Scotian Shelf. Regions of high and low shear and areas of strong and weak flow were resolved using the dynamic height method, and show that there is valuable information in the hydrography that can be used to interpret the static measures of larval abundance; this is especially so where the size of larvae reflects the temporal evolution of spatial patterns that result from the dispersal of larvae from their source (i.e. the dynamics of the circulation). For example, if this was not the case for cod and hake, we would not expect to see an evolution of size along isopycnals (Fig. 7).

The most important physical features of the shelf circulation were qualitatively resolved using the dynamic height contours (Fig. 8) and quantitatively using the optimal and variational interpolations (Fig. 9) derived from the dynamic height estimates. The optimal and variational interpolations provide comparable estimates of the principal currents (e.g. the shelf-slope and coastal current), though the differences suggest that the variational algorithm is preferred when conducting postoperational analyses (e.g. particle tracking). The preference is based on the lower $\gamma^{2}$ statistic and comparability to the seasonally averaged flow resolved using more sophisticated numerical models (Sheng and Thompson, 1996; Han et al., 1997; 
Figure 7. Expanding-symbol representations of larval abundance (number per $100 \mathrm{~m}^{3}$ ) and median total length (mm) associations among water masses characterized by temperature $\left({ }^{\circ} \mathrm{C}\right)$, salinity (psu) and density $\left(\sigma_{t}\right.$, shown by the isopycnals) for cod (a, b), silver hake (c, d) and herring $(e, f)$ on the central Scotian Shelf during 18 Nov. to 01 Dec. 1997.

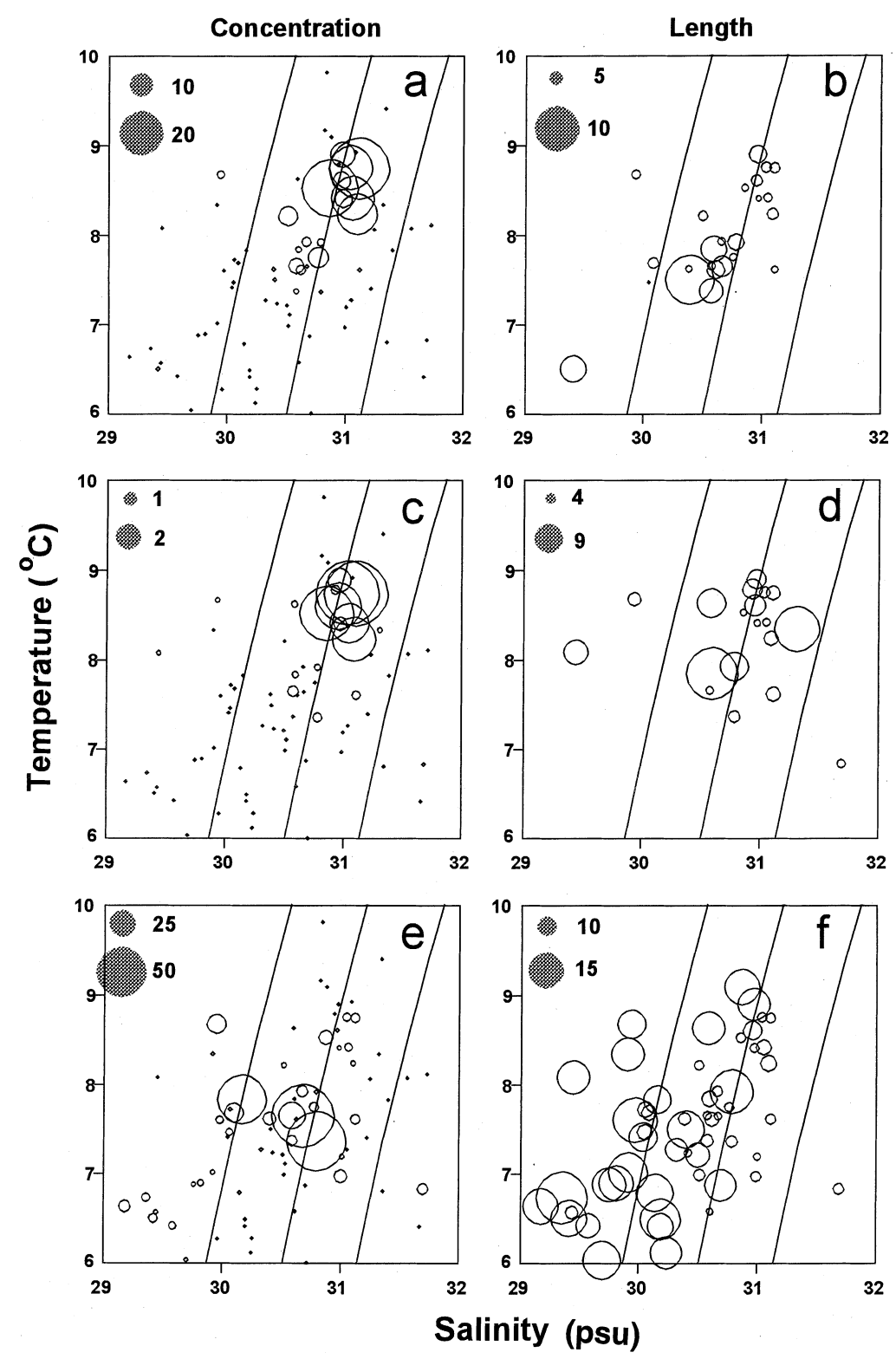

Hannah et al., 2000) and other bank-scale observations in autumn (Thompson and Griffin, 1998).

\section{Inferences from particle tracking}

There was good agreement between the observed (current meters) and inferred (the variational interpolation of dynamic height) flow field and what has been previously modelled for shelf circulation. Thus, we can qualitatively assess, at least for this one realization (Nov. 1997), whether spawning source and the geostrophic circulation over the central Scotian Shelf can most easily explain the variation in the spatial distribution of larval species, size and abundance.
Using the derived flow field, and a simple RungeKutta Lagrangian tracking technique (Hofmann et al., 1991), we numerically tracked 'particles' in the surface layer over a 20 day period, commensurate with the sampling period (Fig. 13), to provide some insight into the mechanisms controlling the distribution of larvae. Particles released seaward of the southern flank of Western Bank were quickly ( $<5$ days) advected away in the shelf-slope current. Other particles along the $70-80 \mathrm{~m}$ isobath on the southern flank (the most likely spawning location for offshore herring) were advected around Western Bank and then northward toward the coastal current. Particles north-west of the crest of Western Bank were retained within an 


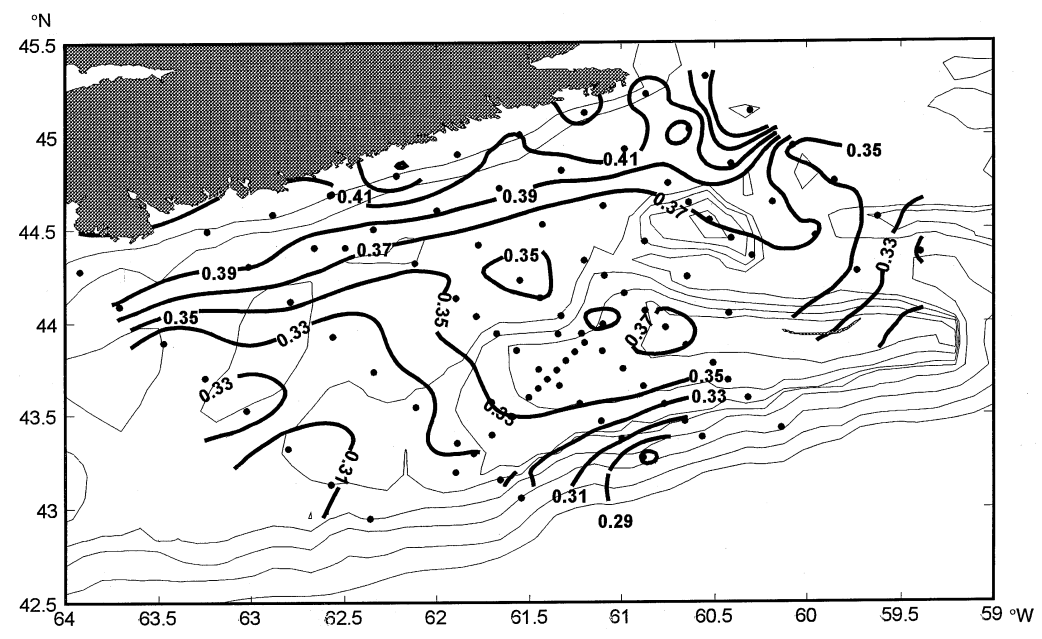

Figure 8. Bathymetric chart of the Scotian Shelf showing dynamic height $(\eta ; \mathrm{m})$ isopleths contoured directly from the station-specific (solid circles) estimates of dynamic height during 18 Nov. to 01 Dec. 1997. Note: contours result from neither the optimal nor the variational interpolation (cf. Fig. 9).

anticyclonic circulation. Particles just north of the crest moved east-south-east but remained near the crest after 20 days, reflecting the cyclonic circulation associated with a local minimum in the dynamic height field in the Cowpen (Fig. 8). Particles entrained in the eastward flow along the northern flank subsequently veered north just west of the northern spur (also observed using drifters in September; Reiss, 1997). In summary, particles released in the surface layer of the Western Bank region in general follow the isopycnals and more specifically the geostrophic flow. Do the distributions of larvae appear to evolve accordingly?

Particle-tracking results can be directly compared with the spatial distributions of larval cod and hake abundance and size (Figs 10, 11). For example, the highest concentrations of hake larvae (Fig. 11a) are within the null circulation north-west of the crest of Western Bank (Figs 9b, 13). The smallest larvae are nearer to the crest (the spawning location) and tend to increase in size toward the north (Fig. 11b), where they would have been carried from their origin and as they grew and became entrained in the geostrophic flow around the periphery of the Bank (Fig. 13). This interpretation is consistent with the shelf-wide distribution of larval sizes relative to the isopycnals (Fig. 7). For example, the sizes of larval cod (Fig. 7b) increase along the lines of constant density and as seen through temporal evolution in the particle tracking (Fig. 13). The same pattern is seen for hake larvae (Fig. 7d), although it is more diffuse owing to the protracted spawning demonstrated by their size range.
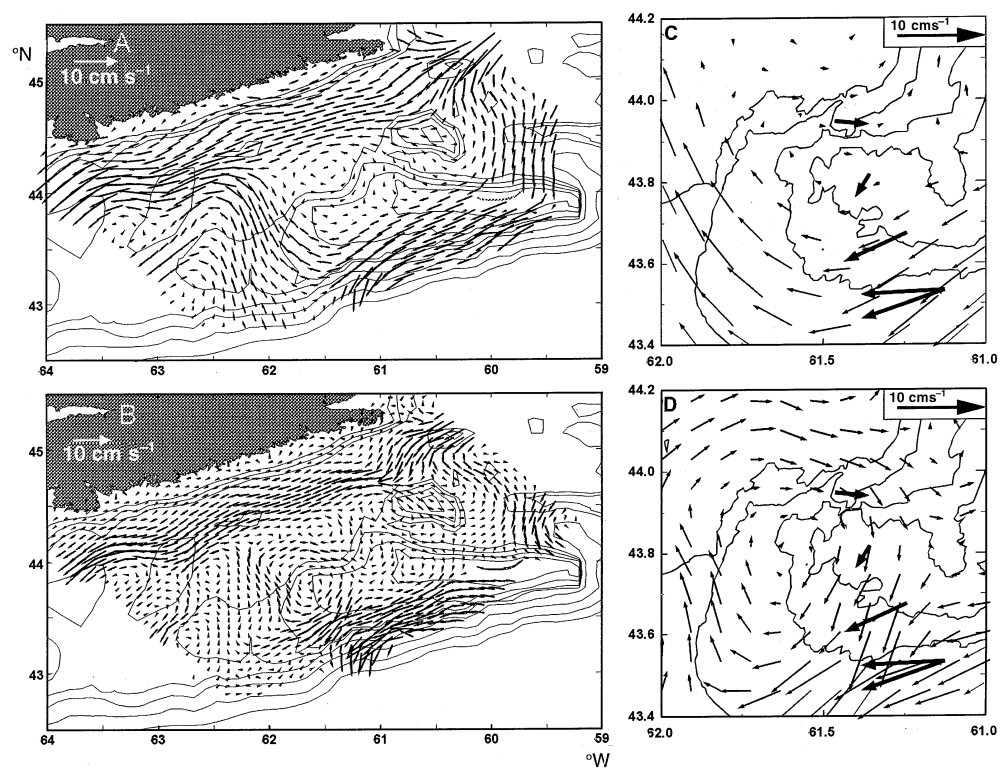

Figure 9. Flow fields derived from the dynamic height method where: (a) results from the optimal interpolation; and (b) results from the variational interpolation algorithm. Comparisons between the observed average (18 Nov. to 01 Dec. 1997) currents at four moorings (thick arrows) are provided for: (c) optimally; and (d) variationally interpolated flow fields (delicate arrows) for the same period on Western Bank. 
Figure 10. Expanding-symbol spatial distributions of: (a) larval cod concentration (number per $100 \mathrm{~m}^{3}$ ); and (b) their median total length $(\mathrm{mm})$ on the central Scotian Shelf during 18 Nov. to 01 Dec. 1997.

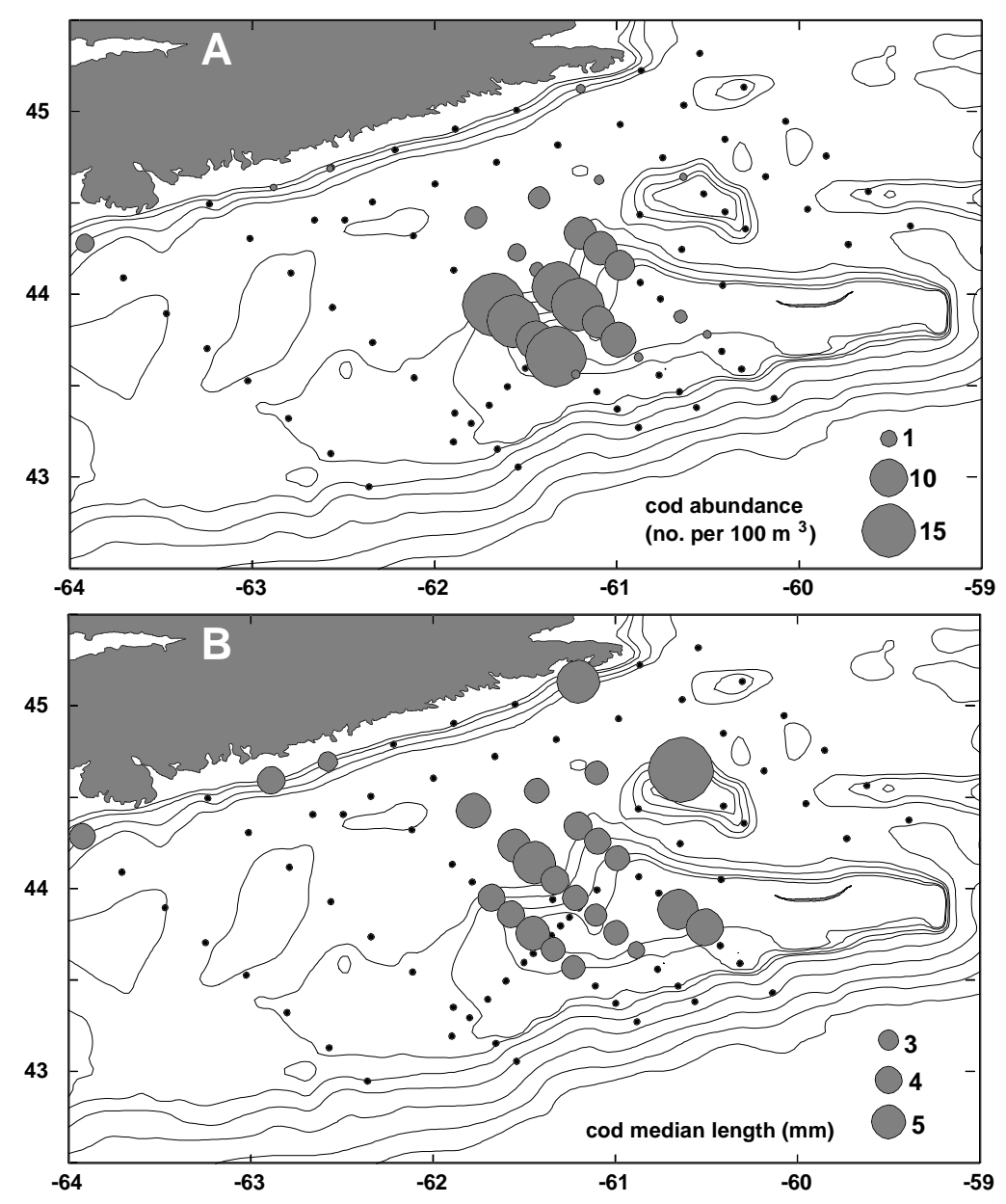

The above interpretations are important for two reasons. First, the only way that larvae of a given origin in T-S space can cross lines of constant density is either to swim across the density gradient (which requires energy and directional cues) or to be advected and mixed among water masses to a new density (which requires the amount of energy that can only be provided through physical forcing), something that we do not see for cod and hake (Fig. 7). What we do see is an evolution of decreasing abundance and increasing size that parallels the isopycnals and corresponds to changing $T$ and $S$ as the water mass is slowly advected and mixed. Second, the constrained spatial distribution of silver hake and cod larvae, coupled with their skewed distributions of size, demonstrates a scale of retention (say $50 \mathrm{~km}$ ), though not centred in the immediate spawning location. It appears that it is simply (but not necessarily only) the spawning location and the physical processes that led to the observed patterns.

The highest concentrations of herring larvae are on the southern flank of Western Bank and inshore of the coastal current (Fig. 12a). However, it appears that the particle tracking is less useful for inferring the transport pathways of larval herring (Fig. 13) relative to cod and hake. This is particularly true for the offshore, where the smallest larvae on Western Bank (a spawning location) increase in size and are more broadly dispersed toward the north (Fig. 12b). So, what may explain the observed offshore abundance and size distribution of herring? It is clear that near the coast, there are multiple spawning sources inshore of the coastal current, as shown by high and spatially variable concentrations of small animals. Multiple spawning sources along the coast are documented (Sameoto, 1971; Crawford, 1980; Anon, 1998). It is also clear that large larvae are widely distributed within the coastal current, where the particle tracking reveals rapid alongshore advection. The band of relatively large herring in the coastal current reflects accumulation of coastal-spawned larvae or advection from upstream sources, or both. Either way, spawning source(s) and the flow field explains most of the pattern along the coast, i.e. the 

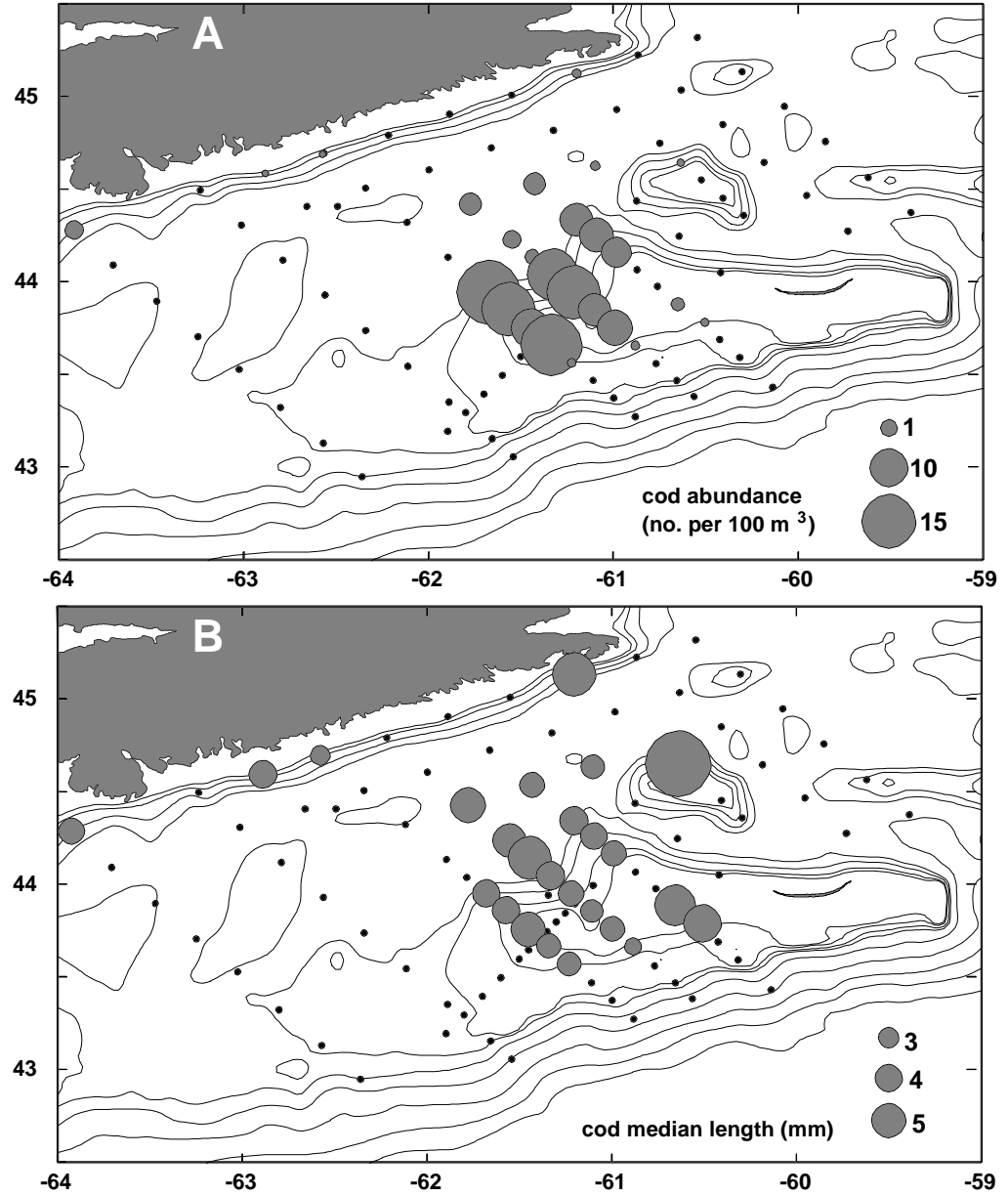

Figure 11. Expanding-symbol spatial distributions of: (a) larval silver hake concentration (number per $100 \mathrm{~m}^{3}$ ); and (b) their median total length $(\mathrm{mm})$ on the central Scotian Shelf during 18 Nov. to 01 Dec. 1997. main axis of the coastal current acts to constrain the seaward dispersion of larvae and defines the seaward boundary of their 'retention' area. If we apply a similar interpretation to the offshore larvae, assuming a single spawning source on Western Bank, then advection in the dominant shelf break current would carry larvae downstream to the west of Western Bank, or seaward, but we did not observe larvae there (Fig. 12). Therefore, we infer that the larvae are transported around the Bank (along the 70-80 m isobath) within the anticyclonic flow (Figs 9, 13). However, it is difficult to infer a retention area, or its size, for herring offshore, especially relative to cod and hake, because cod and hake show a clear pattern in relation to the isopycnals, but herring do not (Fig. 7). In summary, the abundance distributions of cod, hake and herring all show clear patterns that reflect source and flow, whereas the size distributions of cod and hake (but not offshore herring) show an evolution in size along the isopycnals.
Larval assemblages and retention mechanisms

Two larval fish assemblages with different spawning strategies were derived as predicted by Suthers and Frank (1991) for the south-western Scotian Shelf. Despite the obvious pattern in the ordination of the assemblages in T-S space (Fig. 14), neither the assemblages nor their species components were meaningfully correlated with any single state variable (T, S, z, distance from shore, etc.) nor the derived dynamic height $(\eta)$ when treated as a state variable. $\mathrm{PC}$ analyses were useful in distinguishing assemblages and in describing their general association with watermass characteristics (Fig. 14). However, the bivariate correlations between those assemblages and static hydrographic variables offer limited explanatory power in this case. This is because water masses of similar $T$, $\mathrm{S}$ and/or density that exist in different places on the Scotian Shelf can be more or less contiguous along streamlines described by the geostrophic flow. Thus, it is not surprising that state variables in themselves, no 
Figure 12. Expanding-symbol spatial distributions of: (a) larval Atlantic herring concentration (number per $\left.100 \mathrm{~m}^{3}\right)$; and (b) their median total length $(\mathrm{mm})$ on the central Scotian Shelf during 18 Nov. to 01 Dec. 1997.

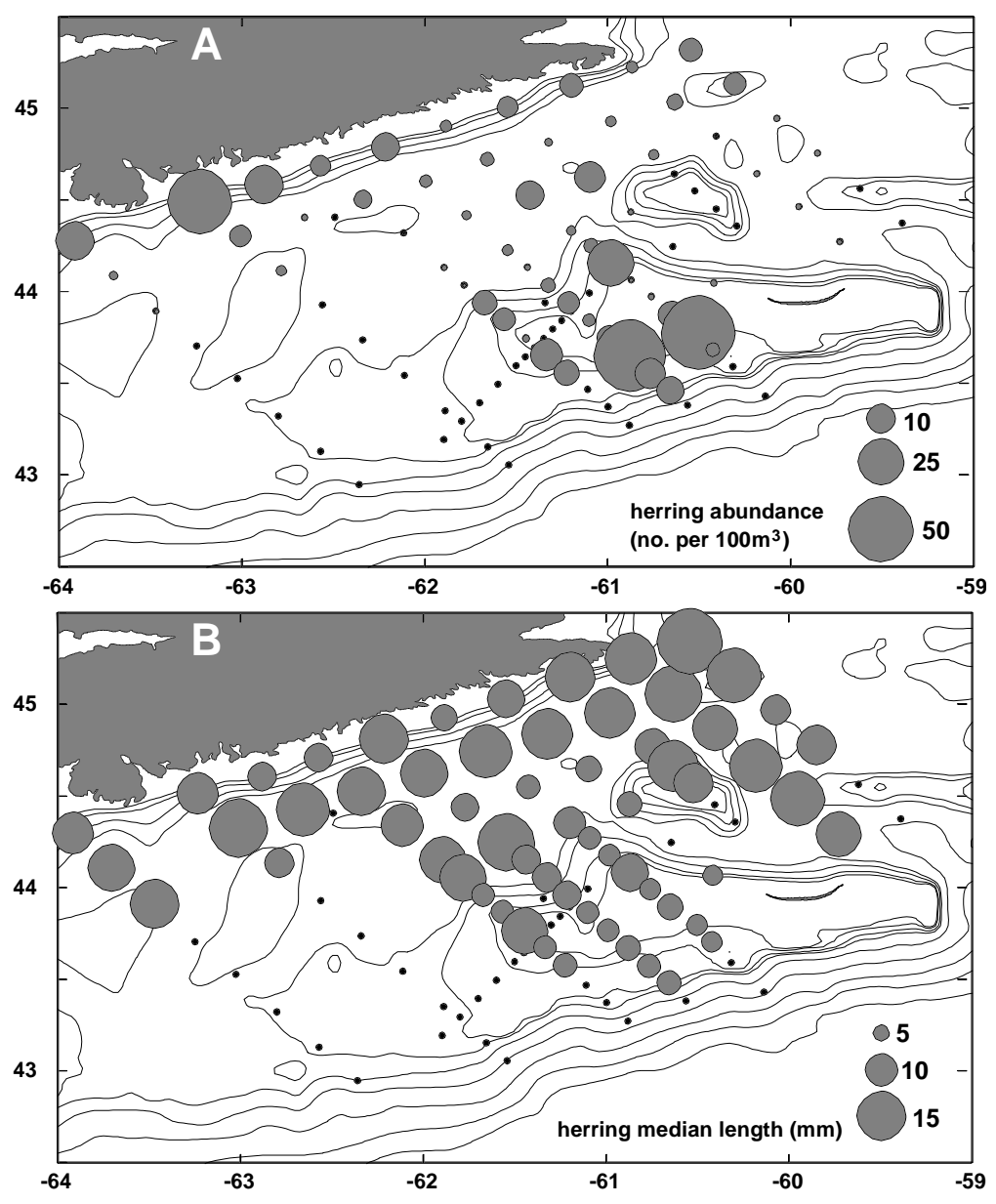

matter how derived, offered limited explanatory power or predictive utility concerning the early life stages - a conclusion similar to that of Cowen et al. (1993) and Dempster et al. (1997). However, greater explanatory power and perhaps predictive utility is offered by the flow field, which is itself defined by several state variables ( $z$, bathymetry, $\mathrm{T}, \mathrm{S}$, etc.).

The dynamic height method described here seems robust for resolving the near-surface geostrophic flow field, and for doing so in near real-time. Therefore, in locations where ageostrophic (e.g. tides, eddy impingement) forcing is weak, the technique can be used to direct adaptive sampling of the plankton where resolving the circulation is necessary to interpret biological observations and to infer processes beyond the level of hydrographic and geographical correlation (as in Cowen et al., 1993). Almost any study that addresses spatial distributions could benefit accordingly. Where the assumptions are not limiting, the dynamic height method can be used to identify regions of shear and high and low flow in near real-time. A rapid broad-scale hydrographic survey prior to biological sampling can lead to a more efficient and effective use of ship-time by identifying the biologically relevant features and their associated time and space scales. Accordingly, an improved testing of hypotheses related to distribution, size, growth and survival of fish larvae should emerge. Further, we argue that relatively rare and large (older) larvae of abundant species should not be easily dismissed as 'outliers', as they represent important tracers of mixing and advection (the time-space history of larval dispersion). Others have successfully used the dynamic height method to track zooplankton in deeper waters where the method is generally considered appropriate (cf. Mackas et al., 1991). This study suggests that similar success is possible in those shallow shelf seas where geostrophic flow dominates.

\section{Hypotheses and predictions}

Contemporary hypotheses attempt to explain variation in recruitment as some function of advection and diffusion from spawning locations (Harden Jones, 1968), geographical retention (Iles and Sinclair, 1982; 


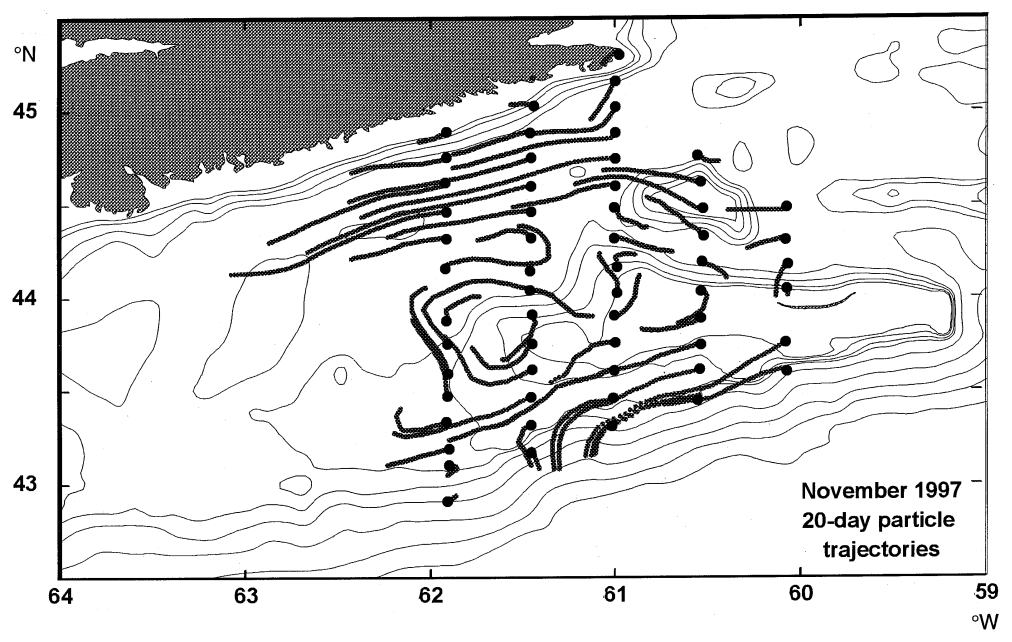

Figure 13. Bathymetric chart of the Scotian Shelf showing the 20 day trajectories (solid lines) for particles released (solid circles) into the surface layer flow field for the period 18 Nov. to 01 Dec. 1997 that was derived from the dynamic height method using the variational interpolation (i.e. Fig. 9b).

Sinclair, 1988) or biologically mediated processes related to differential survival (Lambert, 1984; Lambert and Ware, 1984; Anderson, 1988). Testing the various aspects of these hypotheses is confounded by different scales of several relevant physical and biological process influencing the larval phase. We argue that success in explaining variation in growth, survival or year-class strength, etc. is dependent first on identifying and explaining the variance attributable to physical forces - something we have attempted to achieve here.

Second, the spatial distribution of the size of cod and hake on and around the Bank suggests that the larvae need only to be retained over the crest for a fraction of the larval development period, if at all. Larval hake that are advected off the crest show a growth rate advantage (Jeffrey and Taggart, 2000), and the deeper flanks north of Western Bank are important feeding areas for juvenile cod and hake (Koeller et al., 1989; Sameoto et al., 1994) and settlement areas for juvenile haddock (Frank and Simon, 1998). Thus, we can hypothesize that retention over the Bank need only occur during early development when larvae require food of a certain size or type (McLaren and Avendaño, 1995), and perhaps to be insulated from predation in surrounding water masses (e.g. safe site hypothesis of Frank and Leggett, 1982). Disruption of the near-surface geostrophic circulation, or advection of the retaining water mass as an integral body (e.g. excursions of the geostrophic flow over deeper and potentially predator-rich water) at the wrong time may result in extensive mortality among those larvae of some unknown but critical size. Excursions of integral water masses would imply that
Figure 14. Larval fish community assemblages as derived from principal component analysis and their associations (symbol sizes scaled relatively by concentration) among water masses (temperature, salinity and density as shown by the isopycnals) for the pelagic spawning assemblage (cod, hake and pollock; squares), the benthic spawning assemblage (herring and capelin; triangles) and other species (circles) on the central Scotian Shelf during 18 Nov. to 01 Dec. 1997.

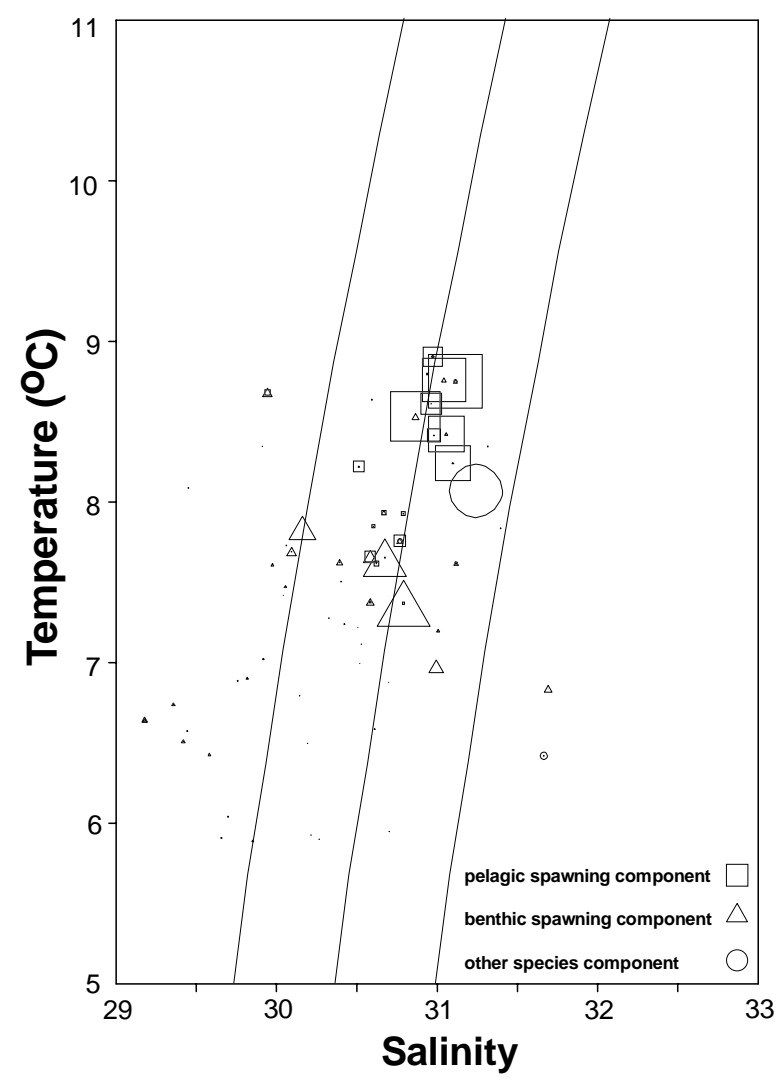


the prey field, feeding and condition of the larvae would remain the same as they were on the Bank and thus on- and off-bank differences in these measures would be negligible, precisely as observed by McLaren et al. (1997) and Lochmann et al. (1997).

Retention of larval fish near marine banks is generally thought to result from physical processes and resultant hydrographic features (e.g. fronts) that limit horizontal diffusion or advection (Bolz and Lough, 1984; O'Boyle et al., 1984; Townsend and Pettigrew, 1996). Our observations of larval distributions and a simple particle-tracking exercise indicate that retention on or near the low-energy offshore bank that we studied results from the interaction of the geostrophic flow and bathymetry without provision for convergence or larval behaviour.

\section{ACKNOWLEDGEMENTS}

We thank the Captain and crew of the CCGS NEEDLER, B. Ruddick, W. Judge, S. Carter, and D. Walsh for their help at sea. We also thank the Captains and crews of the CCGS PARIZEAU and CCGS HUDSON, G. Bugden, D. Hazen, J. Foley, P. Vass, K. Drinkwater, G. Harding and L. Petrie for help in the current-meter deployment and recovery. A. Pickle, E. Arnold, and P. Avendaño provided expertise at sea and in the lab. We are grateful to R. Stephenson and M. Power for support, cooperation and critical appraisals, and especially to $\mathrm{K}$. Thompson for encouraging us to pursue the dynamic height method in operational fisheries oceanography. Funding to CTT, BdeY and I. McLaren was provided by GLOBECCanada, a Research Partnership Network sponsored by the Natural Sciences and Engineering Research Council of Canada. E. Arnold was supported in part by the Nova Scotia Links Student Employment Programme.

\section{REFERENCES}

Anderson, J.T. (1988) A review of size dependent survival during pre-recruit stages of fishes in relation to recruitment. J. Northw. Atl. Fish. Sci. 8:55-66.

Anonymous (1998) 4VWX herring. Dartmouth, Nova Scotia: Dept Fisheries and Oceans Stock Status Rep. B3-03:1-12.

Bolz, G.R. and Burns, B.R. (1996) Age and growth of larval Atlantic herring, Clupea harengus: a comparative study. Fish. Bull. US 94:387-397.

Bolz, G.R. and Lough, R.G. (1984) Retention of ichthyoplankton in the Georges Bank region during the autumn-winter seasons, 1971-1977. J. Northw. Atl. Fish. Sci. 5:33-45.

Campana, S.E., Smith, S.J. and Hurley, P.C.F. (1989) A drift retention dichotomy for larval haddock (Melanogrammus aeglefinus) spawned on Browns Bank. Can. J. Fish. Aquat. Sci. 46:93-102.

Chenoweth, S.B., Libby, D.A., Stephenson, R.L. and Power, M.J. (1989) Origin and dispersion of larval herring (Clupea harengus) in coastal waters of eastern Maine and southwestern New Brunswick. Can. J. Fish. Aquat. Sci. 46:624-632.

Cong, L., Sheng, J. and Thompson, K.T. (1996) A retrospective study of particle retention on the outer banks of the Scotian Shelf, 1956 -1993. Can. Tech. Report Hydro. EB Ocean Sci. $170: 1-140$

Cowen, R.K., Hare, J.A. and Fahay, M.P. (1993) Beyond hydrography: can physical processes explain larval fish assemblages within the Middle Atlantic Bight. Bull. Mar. Sci. 53:567-687.

Crawford, R. (1980) A biological analysis of herring from the Atlantic coast of Nova Scotia and eastern Northumberland Strait. Nova Scotia Dept Fisheries MSS EO Tech. Rep. Ser. 80-03:1-145.

Csanady, G.T. (1979) The pressure field along the western margin of the North Atlantic. J. Geophys. Res. 84:49054915.

Cushing, D.H. (1973) The natural regulation of fish populations. In: Sea Fisheries Research. F.R. Harden-Jones (ed). London: Elek Science, pp. 389-412.

Cushing, D.H. (1990) Plankton production and year-class strength in fish populations: an update of the Match/ Mis-match hypothesis. Adv. Mar. Biol. 26:249-293.

Dempster, T., Gibbs, M.T., Rissik, D. and Suthers, I.M. (1997) Beyond hydrography: daily ichthyoplankton variability and short term oceanographic events on the Sydney continental shelf. Cont. Shelf Res. 17:1461-1481.

Fortier, L. and Villeneuve, A. (1996) Cannibalism and predation on fish larvae by larvae of Atlantic mackerel, Scomber scombrus: trophodynamics and potential impact on recruitment. Fish. Bull. US 94:268-281.

Frank, K.T. and Leggett, W.C. (1982) Coastal water mass replacement: its effect on zooplankton dynamics and the predator-prey complex associated with larval capelin (Mallotus villosus). Can. J. Fish. Aquat. Sci. 39:991-1003.

Frank, K.T. and Simon, J.E. (1998) An evaluation of the Emerald/Western Bank juvenile haddock closed area. Can. Stock Assessment Secretariat Res. Doc. 98/53:1-57.

Gandin, L.S. (1965) Objective Analysis of Meteorological Fields. Jerusalem, Israel: Program for Scientific Translations, $242 \mathrm{pp}$.

Gill, A.E. (1982) Atmosphere Ocean Dynamics. Academic Press, New York, 662 pp.

Griffin, D.A. and Thompson, K.R. (1996) The adjoint method of data assimilation used operationally for shelf circulation. J. Geophys. Res. 101:3457-3478.

Han, G., Hannah, C.G., Loder, J.W. and Smith, P.C. (1997) Seasonal variation of the three-dimensional mean circulation over the Scotian Shelf. J. Geophys. Res. 102:10111025.

Hannah, C.G., Shore, J.A., Loder, J.W. and Naimie, C.E. (2000) Seasonal circulation on the western and central Scotian Shelf. J. Phys. Oceanogr. (in press).

Harden Jones, F.R. (1968) Fish Migration. London: Edward Arnold, 325 pp.

Heath, M. (1990) Segregation of herring larvae from inshore and offshore spawning grounds in the northwestern North Sea - implications for stock structure. Neth. J. Sea Res. 25:267-278. 
Heath, M., Henderson, E.W. and Baird, D.L. (1988) Vertical distribution of herring larvae in relation to physical mixing and illumination. Mar. Ecol. Progr. Ser. 47:211-228.

Helbig, J.A. and Pepin, P. (1998a) Partitioning the influences of physical processes on the estimation of ichthyoplankton mortality rates. I. Theory. Can. J. Fish. Aquat. Sci. 55:2189_ 2205.

Helbig, J.A. and Pepin, P. (1998b) Partitioning the influences of physical processes on the estimation of ichthyoplankton mortality rates. II. Application to simulated and field data. Can. J. Fish. Aquat. Sci. 55:2206-2220.

Helland-Hansen, B. (1934) The Sognefjord section. Oceanographic observations in the northernmost part of the North Sea and southern part of the Norwegian Sea. In: James Johnstone Memorial Volume. Lancashire Sea-Fish Laboratory (ed). Liverpool: University of Liverpool Press, pp. 257-274.

Hjort, J. (1914) Fluctuations in the great fisheries of northern Europe viewed in the light of biological research. Rapp. P.-v. Réun. Cons. Int. Explor. Mer 20:1-288.

Hofmann, E.E., Hedstrom, K.S., Moisan, J.R., Haidvogel, D.B. and Mackas, D.L. (1991) Use of simulated drifter tracks to investigate general transport patterns and residence times in the coastal transition zone. J. Geophys. Res. 96:15 04115050.

Iles, D. and Sinclair, M. (1982) Atlantic herring: stock discreteness and abundance. Science 215:627-633.

Jeffrey, J.A. and Taggart, C.T. (in press) Growth variation and water mass associations in larval silver hake (Merluccius bilinearis) on the Scotian Shelf. Can. J. Fish. Aquat. Sci. 57: (in press).

Kingsford, M.J. (1990) Linear oceanographic features: a focus for research on recruitment processes. Aust. J. Ecol. 15:391-401.

Koeller, P.A., Coates-Markle, L. and Neilson, J.D. (1989) Feeding ecology of juvenile (age-0) silver hake (Merluccius bilinearis) on the Scotian Shelf. Can. J. Fish. Aquat. Sci. 46:1762-1768.

Lambert, T.C. (1984) Larval cohort succession in herring (Clupea harengus) and capelin (Mallotus villosus). Can. J. Fish. Aquat. Sci. 41:1552-1564.

Lambert, T.C. and Ware, D.M. (1984) Reproductive strategies of demersal and pelagic spawning fish. Can. J. Fish. Aquat. Sci. 41:1565-1569.

Larson, N.G. (1993) Calibration of oceanographic CTD instruments: methods and traceability. J. Adv. Mar. Techn. Conf. 7:3-13.

Lochmann, S.E., Taggart, C.T., Griffin, D.A., Thompson, K.R. and Maillet, G.A. (1997) Abundance and condition of larval cod (Gadus morhua) at a convergent front on Western Bank, Scotian Shelf. Can. J. Fish. Aquat. Sci. 54:1461-1479.

Loder, J.W., Ross, C.K. and Smith, P.C. (1988) A space- and time-scale characterization of circulation and mixing over submarine banks, with application to the Northwestern Atlantic continental shelf. Can. J. Fish. Aquat. Sci. 45:1860-1885.

Mackas, D.L., Washburn, L. and Smith, S.L. (1991) Zooplankton community pattern associated with a California Current cold filament. J. Geophys. Res. 96(C8):14 781-14 797.

McIntosh, P.C. (1990) Oceanographic data interpolation: objective analysis and splines. J. Geophys. Res. 95:13 529_ 13541.

McLaren, I.A. and Avendaño, P. (1995) Prey field and diet of larval cod on Western Bank, Scotian Shelf. Can. J. Fish. Aquat. Sci. 52:448-463.
McLaren, I.A., Avendaño, P., Taggart, C.T. and Lochmann, S.E. (1997) Feeding by larval cod in different water masses on Western Bank, Scotian Shelf. Fish. Oceanogr. 6:250-265.

Meekan, M.G. and Fortier, L. (1996) Selection for fast growth during the larval life of Atlantic cod Gadus morhua on the Scotian Shelf. Mar. Ecol. Progr. Ser. 137:25-37.

O'Boyle, R.N., Sinclair, M., Conover, M.J., Mann, K.H. and Kohler, A.C. (1984) Temporal and spatial distribution of ichthyoplankton communities on the Scotian Shelf in relation to biological, hydrological, and physiographic features. Rapp. P.-v. Réun. Cons. Int. Explor. Mer 183:27-40.

Okubo, A. (1993) The role of diffusion and related physical processes in dispersal and recruitment of marine populations. In: The Bio-Physics of Marine Larval Dispersal. P.W. Sammarco and M.L. Heron (eds). Washington, DC: Am. Geophysical Union, pp. 5-32.

Panteleev, G.G. and Yaremchuk, M.I. (1989) A procedure for interpolating current speed observations at automated buoy stations. Oceanology 29:298-301.

Pingree, R.D., Forster, G.R. and Morrison, G.K. (1974) Turbulent convergent tidal fronts. J. Mar. Biol. Ass. UK 54:469-479.

Polgar, T.T. (1981) Larval retention: transport and behavior, or differential mortality? Estuaries 4:276-277.

Pond, S. and Pickard, G.L. (1983) Introductory Dynamical Oceanography, 2nd edn. Oxford, UK: Pergamon Press, 329 pp.

Posgay, J.A. and Marak, R.R. (1980) The MARMAP bongo zooplankton samplers. J. Northwest Atl. Fish. Sci. 1:91-99.

Power, M.J. (1998) Mission report CCGS Alfred Needler mission 97-070. St Andrews, New Brunswick: Dept Fisheries and Oceans, 1-6.

Reiss, C.S. (1997) Cruise and data summary: DREA-cruise Q-242 Western Bank, September 15-26, 1997. Halifax, Nova Scotia: Dalhousie University, Dept Oceanography, GLOBEC-CANADA Western Bank Rep. 1997/2:1-7.

Sameoto, D.D. (1971) The distribution of herring (Clupea harengus L.) larvae along the southern coast of Nova Scotia with some observations on the ecology of herring larvae and the biomass of macrozooplankton on the Scotian Shelf. Tech. Rep. Fish. Res. Bd Can. 252:1-72.

Sameoto, D.D., Neilson, J.D. and Waldron, D. (1994) Zooplankton prey selection by juvenile fish in Nova Scotian shelf waters. J. Plank. Res. 16:1003-1019.

Sanderson, B. (1995) Structure of an eddy measured with drifters. J. Geophys. Res. 100:6761-6776.

Sasaki, Y. (1970) Some basic formalisms in numerical variational analysis. Mon. Wea. Rev. 98:875-883.

Sheng, J. and Thompson, K.R. (1996) A robust method for the diagnosing of regional shelf circulation from scattered density profiles. J. Geophys. Res. 101:25 647-25 659.

Sinclair, M. (1988) Marine Populations. An Essay on Population Regulation and Speciation. Seattle, WA: University of Washington Press, 252 pp.

Sinclair, M. and Iles, D. (1985) Atlantic herring (Clupea harengus) distributions in the Gulf of Maine - Scotian Shelf area in relation to oceanographic features. Can. J. Fish. Aquat. Sci. 42:880-887.

Smith, W.G. and Morse, W.W. (1985) Retention of larval haddock, Melanogrammus aeglefinus in the Georges Bank region, a gyre-influenced spawning area. Mar. Ecol. Progr. Ser. 24:1-13.

Stephenson, R.L. and Power, M.R. (1988) Semidiel vertical movements in Atlantic herring Clupea harengus larvae: 
a mechanism for larval retention. Mar. Ecol. Progr. Ser. 50:3-11.

Stephenson, R.L. and Power, M.R. (1989) Observations on herring larvae retained in the Bay of Fundy: variability in vertical movements and position of the patch edge. Rapp. P.-v. Réun. Cons. Int. Explor. Mer 191:177-183.

Suthers, I.A. and Frank, K.T. (1991) Comparative persistence of marine fish larvae from pelagic and demersal eggs off southwestern Nova Scotia, Canada. Mar. Biol. 108: $175-184$.

Taggart, C.T. and Frank, K.T. (1991) Perspectives on larval fish ecology and recruitment processes: probing the scales of relationships. In: Large Marine Ecosystems: Patterns, Processes and Yields (AAAS Selected Symposium Series). K. Sherman and L.M. Alexander (eds). Washington, DC: Am. Assoc. Advancement Science, pp. 151-164.
Taggart, C.T., Thompson, K.R., Maillet, G.R., Lochmann, S.E. and Griffin, D.E. (1996) Abundance and distribution of larval cod (Gadus morhua) and zooplankton in a gyre-like water mass on the Scotian Shelf. In: Proc. Int. Workshop on Survival Strategies in Early Life Stages of Marine Resources. Y.Y. Watanabe and Y. Oozecki (eds). Rotterdam, Holland: A.A. Balkema, pp. 155-173.

Thompson, K.R. and Griffin, D.A. (1998) A model of the circulation on the outer Scotian Shelf with open boundary conditions inferred by data assimilation. J. Geophys. Res. 103(C5):30 641-30 660 .

Thompson, K.R. and Sheng, J. (1997) Subtidal circulation on the Scotian Shelf: assessing the hindcasting skill of a linear, barotropic model. J. Geophys. Res. 102(C11):24 978-25 003.

Townsend, D.A. and Pettigrew, N.G. (1996) Frontal currents and the transport of larval fish. Deep-Sea Res. 43:1773-1792. 


\section{Errata}

Reiss, C.S., Panteleev, G., Taggart, C.T., Sheng, J., deYoung, B. Observations on larval fish transport and retention on the Scotian Shelf in relation to geostrophic circulation. Fisheries Oceanography 2000; 9:195-213.

In the above paper, Figure 11 was published incorrectly. The corrected version appears below:
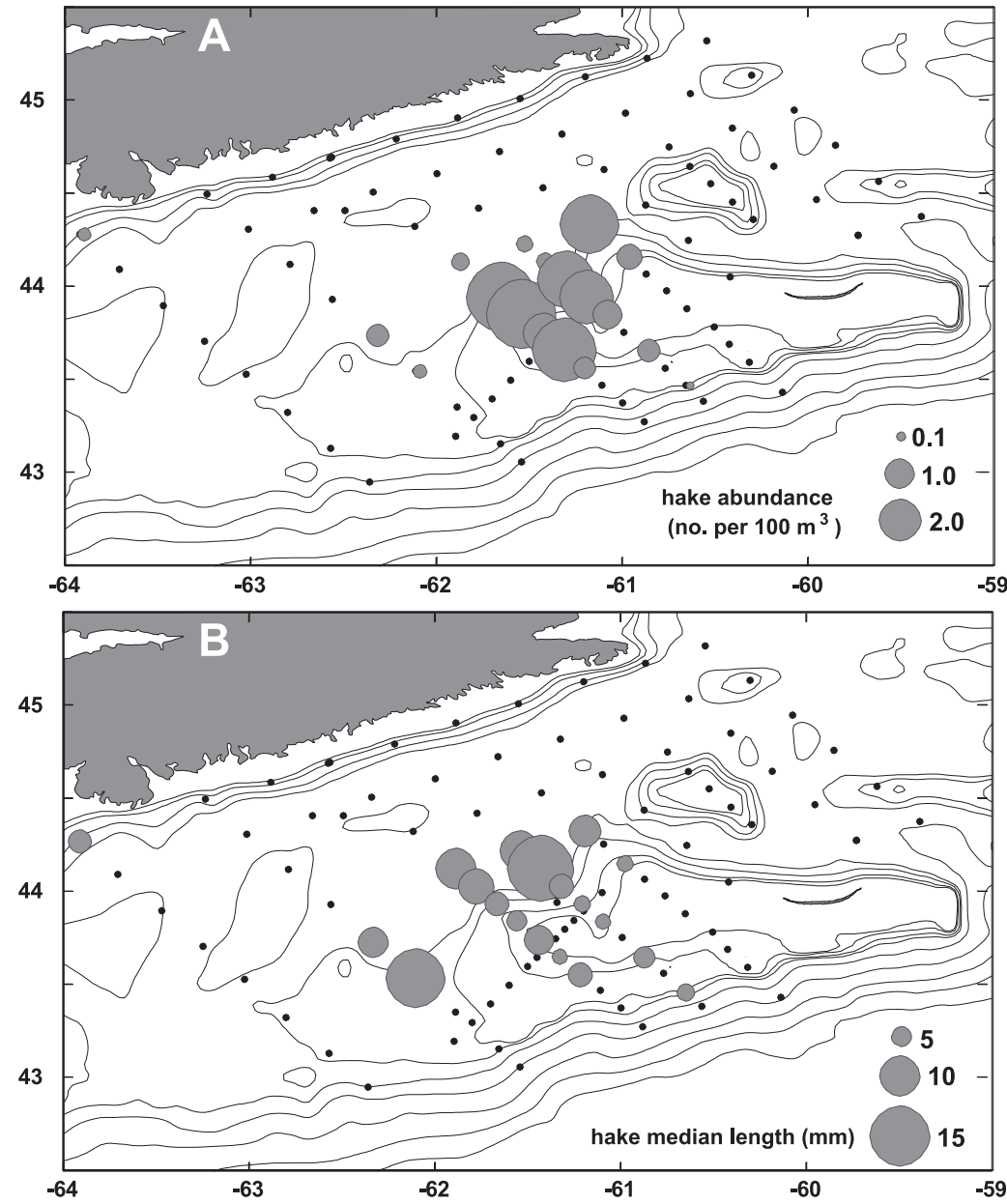

Figure 11. Expanding-symbol spatial distributions of: (A) larval silver hake concentration (number per $100 \mathrm{~m}^{3}$ ); and (B) their median total length $(\mathrm{mm})$ on the central Scotian Shelf during 18 Nov. to 01 Dec. 1997. 